
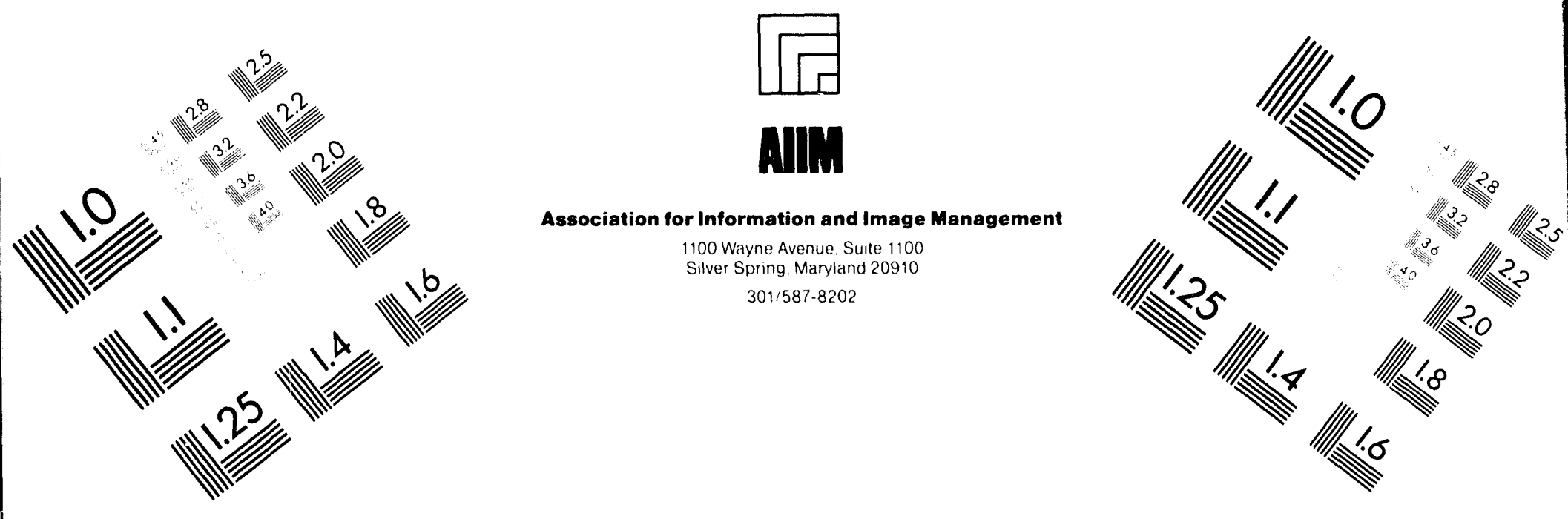

\title{
Centimurer
}

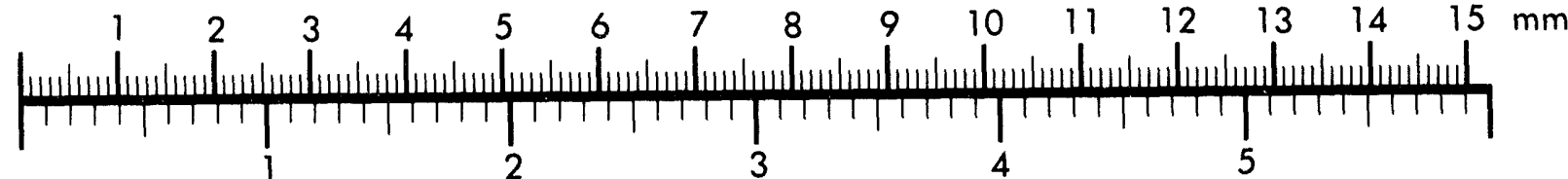
Inches
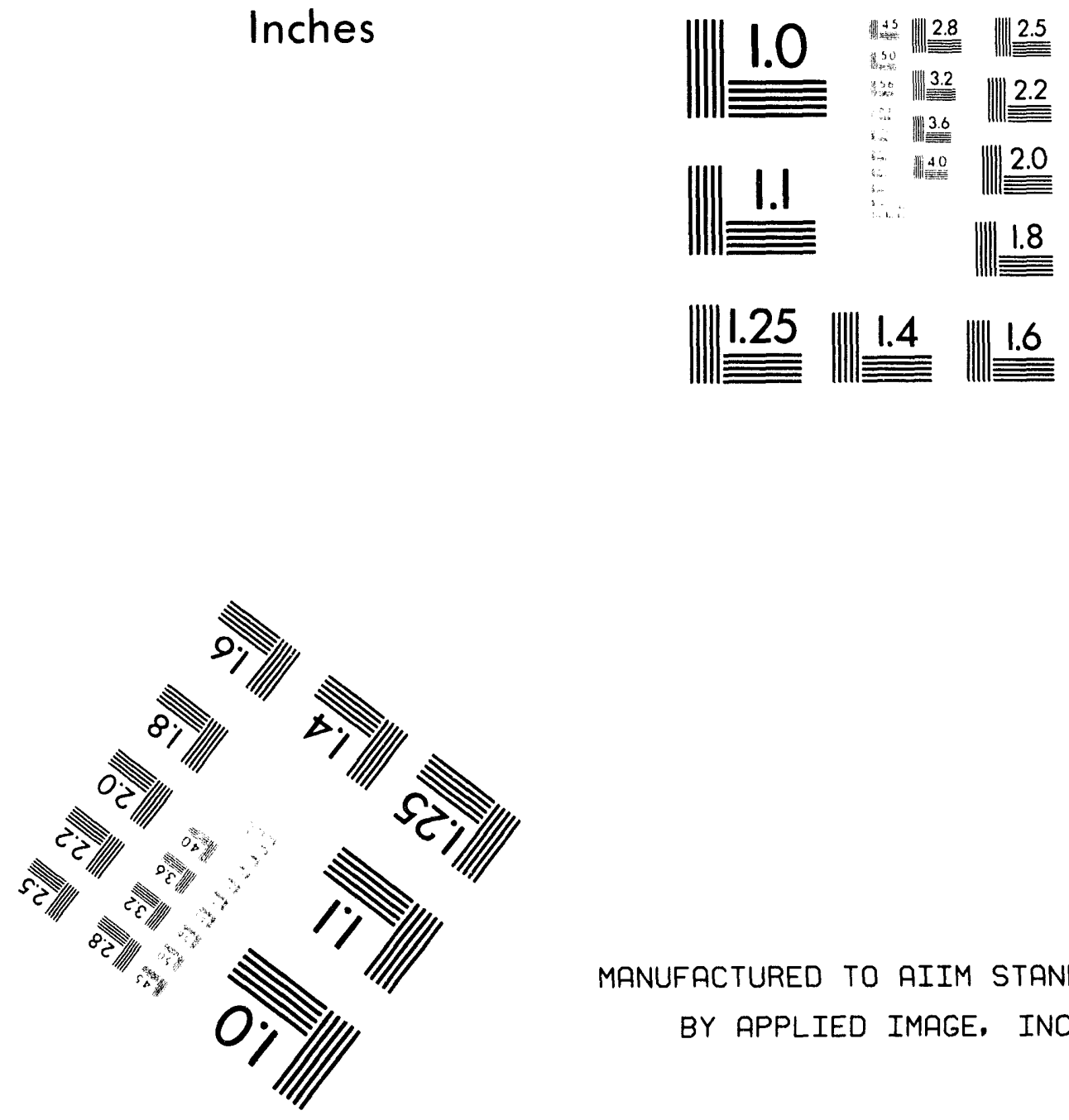

MANUFACTURED TO AIIM STANDARDS BY APPLIED IMAGE, INC.

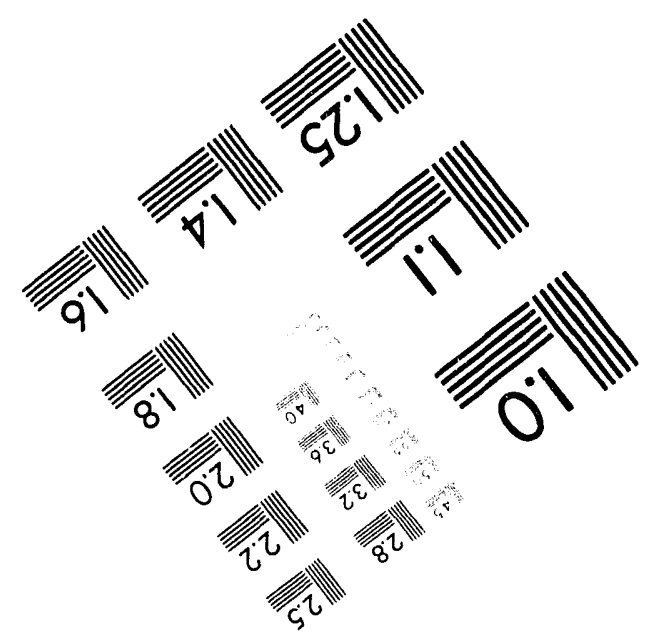



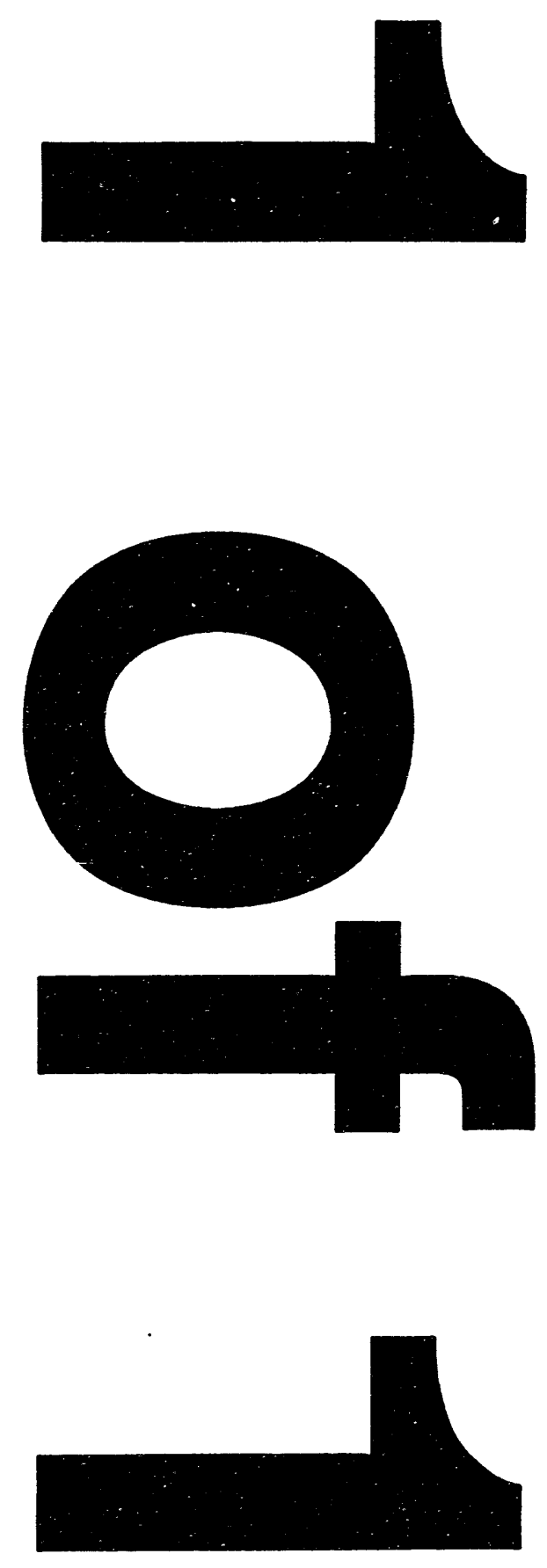


\section{Potential Benefits of Oxygen-Enriched Intake Air in a Vehicle Powered by a Spark-Ignition Engine}

by H.K. Ng and R.R. Sekar

Center for Transportation Research, Energy Systems Division, Argonne National Laboratory, 9700 South Cass Avenue, Argonne, Illinois 60439

April 1994

Work sponsored by United States Department of Energy, Office of Transportation Technologies

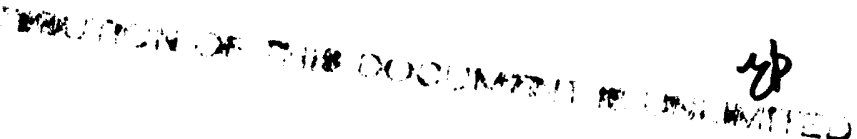


ACKNOWLEDGMENTS $\ldots \ldots \ldots \ldots \ldots \ldots \ldots \ldots \ldots \ldots \ldots \ldots$ vi

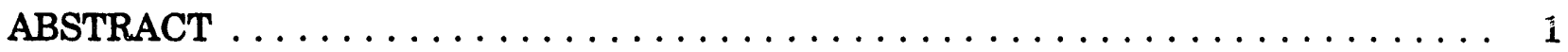

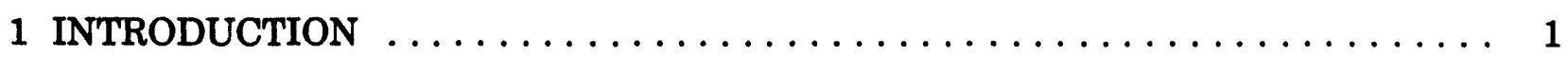

2 EXPERIMENTAL SETUP AND TEST PROCEDURES $\ldots \ldots \ldots \ldots \ldots \ldots \ldots$

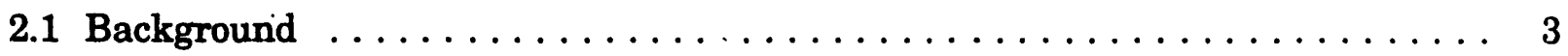

2.2 Oxygen-Enrichment System $\ldots \ldots \ldots \ldots \ldots \ldots \ldots \ldots \ldots \ldots \ldots \ldots \ldots \ldots \ldots \ldots \ldots$

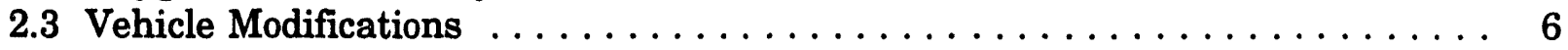

2.4 FTP Emissions Test Procedures $\ldots \ldots \ldots \ldots \ldots \ldots \ldots \ldots \ldots \ldots \ldots \ldots \ldots \ldots \ldots$

2.5 Hydrocarbon Speciation Techniques $\ldots \ldots \ldots \ldots \ldots \ldots \ldots \ldots \ldots \ldots$

3 EXPERIMENTAL RESULTS AND DISCUSSION $\ldots \ldots \ldots \ldots \ldots \ldots \ldots$

3.1 Vehicle Performance $\ldots \ldots \ldots \ldots \ldots \ldots \ldots \ldots \ldots \ldots \ldots \ldots \ldots$

3.2 Engine-Out Emissions $\ldots \ldots \ldots \ldots \ldots \ldots \ldots \ldots \ldots \ldots \ldots \ldots \ldots \ldots \ldots$

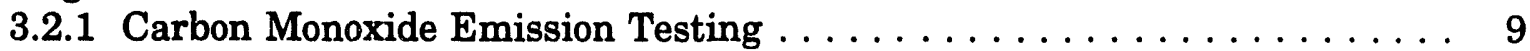

3.2.2 Hydrocarbon Emission Testing $\ldots \ldots \ldots \ldots \ldots \ldots \ldots \ldots \ldots \ldots \ldots$

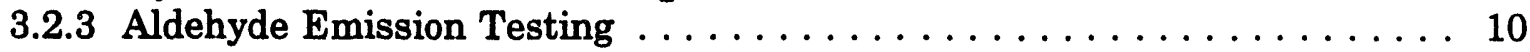

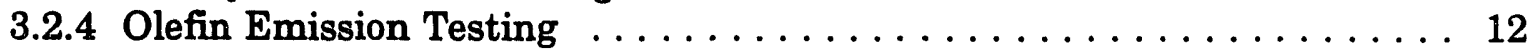

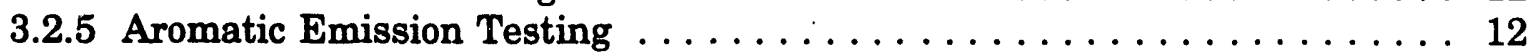

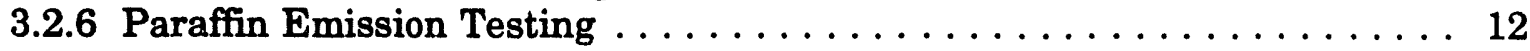

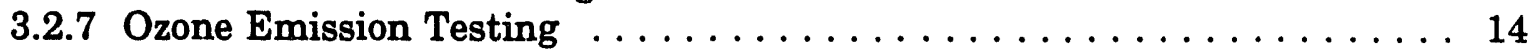

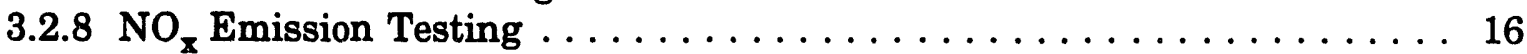

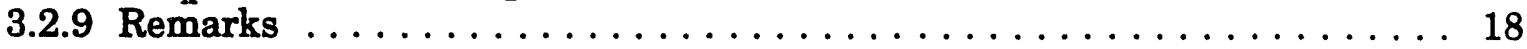

3.3 Catalytic Converter-Out Emissions $\ldots \ldots \ldots \ldots \ldots \ldots \ldots \ldots \ldots \ldots \ldots \ldots \ldots$

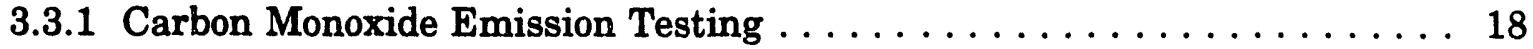

3.3.2 Hydrocarbon Emission Testing $\ldots \ldots \ldots \ldots \ldots \ldots \ldots \ldots \ldots \ldots \ldots \ldots \ldots \ldots$

3.3.3 Aldehyde Emission Testing $\ldots \ldots \ldots \ldots \ldots \ldots \ldots \ldots \ldots \ldots \ldots 20$

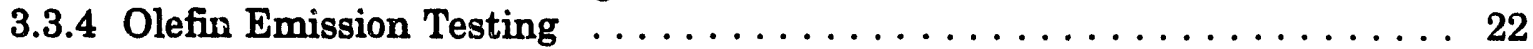

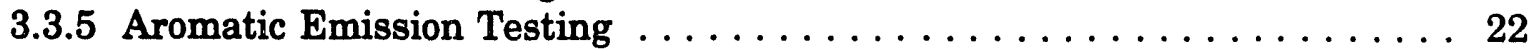

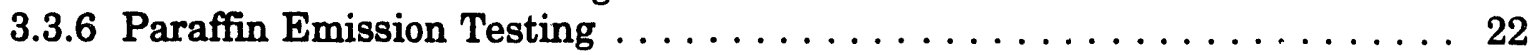

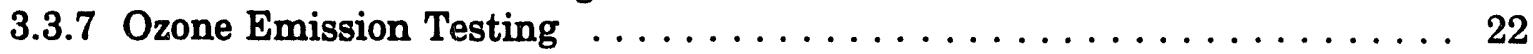

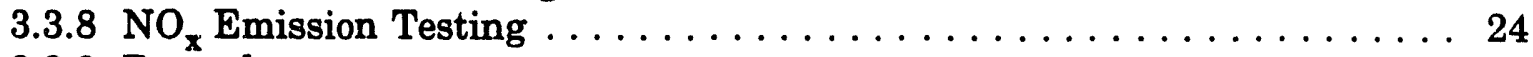

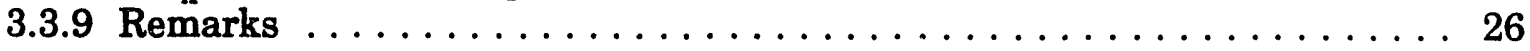

3.4 Emission Calculations Using Oxygen Enrichment

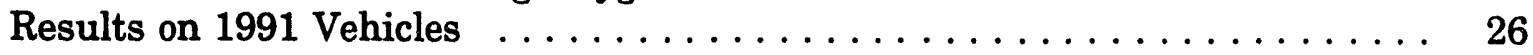

4 CONCLUSIONS AND RECOMMENDATIONS $\ldots \ldots \ldots \ldots \ldots \ldots \ldots \ldots$

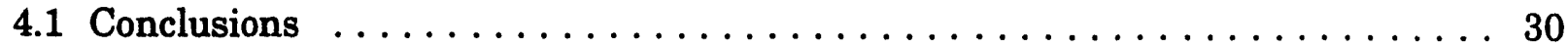

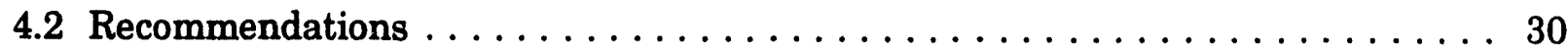




\section{CONTENTS (Cont.)}

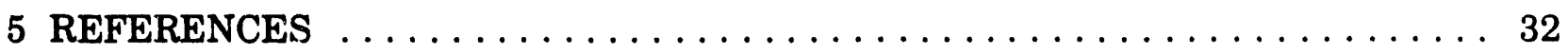

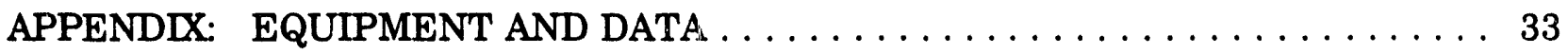

\section{FIGURES}

2.1 Diagram of Oxygen-Enrichment System $\ldots \ldots \ldots \ldots \ldots \ldots \ldots$

2.2 Stability of Oxygen-Enrichment System $\ldots \ldots \ldots \ldots \ldots \ldots$

3.1 Effects of Oxygen-Enriched Intake Air on Engine-Out CO Emissions $\ldots \ldots \ldots$

3.2 Effects of Oxygen-Enriched Intake Air on Engine-Out Hydrocarbon

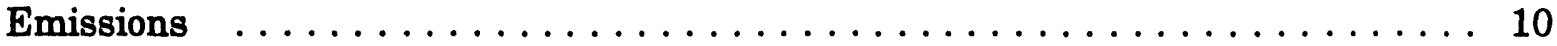

3.3 Effects of Oxygen-Enriched Intake Air on Engine-Out Aldehyde Emissions . . . . 11

3.4 Effects of Oxygen-Enriched Intake Air on Engine-Out Olefin Emissions . . . . . 13

3.5 Effects of Oxygen-Enriched Intake Air on Engine-Out Aromatic Emissions . . . . 14

3.6 Effects of Oxygen-Enriched Intake Air on Engine-Out Paraffin Emissions . . . . 15

3.7 Effects of Oxygen-Enriched Intake Air on Engine-Out Ozone Emissions $\ldots \ldots 16$

3.8 Effects of Oxygen-Enriched Intake Air on Engine-Out Ozone Reductions $\ldots \ldots \ldots 17$

3.9 Effects of Oxygen-Enriched Intake Air on Engine-Out $\mathrm{NO}_{\mathrm{x}}$ Emissions $\ldots \ldots \ldots 17$

3.10 Effects of Oxygen-Enriched Intake Air on Catalytic Converter-Out CO Emissions . . . . . . . . . . . . . . . . . . . . . 19

3.11 Effects of Oxygen-Enriched Intake Air on Catalytic Converter-Out Hydrocarbon Emissions . . . . . . . . . . . . . . . . 20

3.12 Effects of Oxygen-Enriched Intake Air on Catalytic Converter-Out

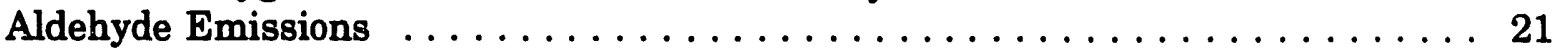

3.13 Effects of Oxygen-Enriched Intake Air on Catalytic Converter-Out

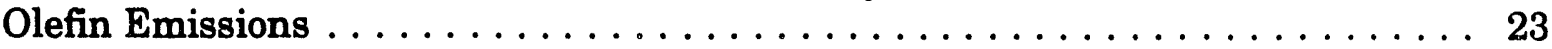

3.14 Effects of Oxygen-Enriched Intake Air on Catalytic Converter-Out Aromatic Emissions $\ldots \ldots \ldots \ldots \ldots \ldots \ldots \ldots \ldots$ 


\section{FIGURES (Cont.)}

3.15 Effects of Oxygen-Enriched Intake Air on Catalytic Converter-Out Paraffin Emissions . . . . . . . . . . . . . . . . . . . . . . . . 25

3.16 Effects of Oxygen-Enriched Intake Air on Catalytic Converter-Out

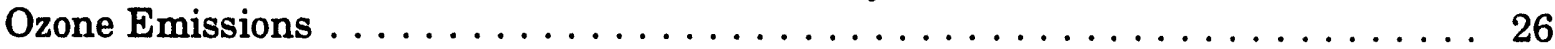

3.17 Effects of Oxygen-Enriched Intake Air on Catalytic Converter-Out

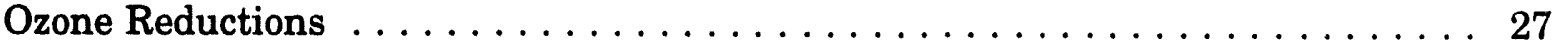

3.18 Effects of Oxygen-Enriched Intake Air on Catalytic Converter-Out

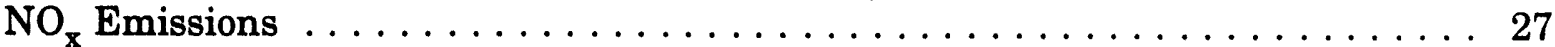

3.19 Potential of Oxygen-Enriched Intake Air to Meet 2004 Standards . . . . . . . . . 29

A.1 Total Oxygen Enrichment System $\ldots \ldots \ldots \ldots \ldots \ldots \ldots \ldots \ldots \ldots \ldots$

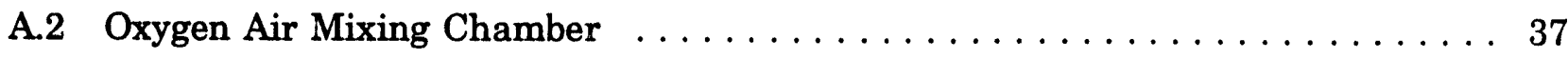

\section{TABLES}

A.2.1 Engine-Out Emissions $\ldots \ldots \ldots \ldots \ldots \ldots \ldots \ldots \ldots \ldots \ldots \ldots \ldots \ldots$

A.2.2 Averaged Engine-Out Emissions $\ldots \ldots \ldots \ldots \ldots \ldots \ldots \ldots \ldots \ldots \ldots$

A.2.3 Catalytic Converter-Out Emissions $\ldots \ldots \ldots \ldots \ldots \ldots \ldots \ldots \ldots \ldots \ldots$. . . 40

A.2.4 Averaged Catalytic Converter-Out Emissions $\ldots \ldots \ldots \ldots \ldots \ldots \ldots \ldots$

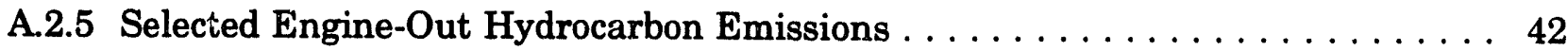

A.2.6 Averaged Engine-Out Hydrocarbon Emissions $\ldots \ldots \ldots \ldots \ldots \ldots \ldots \ldots \ldots$

A.2.7 Selected Catalytic Converter-Out Hydrocarbon Emissions . . . . . . . . . . 44

A.2.8 Averaged Catalytic Converter-Out Hydrocarbon Emissions $\ldots \ldots \ldots \ldots \ldots \ldots 45$ 


\section{ACKNOWLEDGMENTS}

The authors wish to acknowledge the support and guidance of the U.S. Department of Energy, Office of Transportation Technologies. The authors also wish to acknowledge the personnel of AutoResearch Laboratories and the National Renewable Energy Laboratory. 


\title{
POTENTIAL BENEFITS OF OXYGEN-ENRICHED INTAKE AIR IN A VEHICLE POWERED BY A SPARK-IGNITION ENGINE
}

by

\author{
H.K. Ng and R.R. Sekar
}

\begin{abstract}
A production vehicle powered by a spark-ignition engine (3.1-L Chevrolet Lumina, model year 1990) was tested. The test used oxygenenriched intake air containing 25 and $28 \%$ oxygen by volume to determine (1) if the vehicle would run without difficulties and (2) if emissions benefits would result. Standard Federal Test Procedure (FTP) emissions test cycles were run satisfactorily. Test results of catalytic converter-out emissions (emissions out of the converter) showed that both carbon monoxide and hydrocarbons were reduced significantly in all three phases of the emissions test cycle. Test results of engine-out emissions (emissions straight out of the engine, with the converter removed) showed that carbon monoxide was significantly reduced in the cold phase. All emission test results were compared with those for normal air (21\% oxygen). The catalytic converter also had an improved carbon monoxide conversicia efficiency under the oxygen-enriched-air conditions. Detailed results of hydrocarbon speciation indicated large reductions in 1,3-butadiene, formaldehyde, acetaldehyde, and benzene from the engine with the oxygen-enriched air. Catalytic converterout ozone was reduced by $60 \%$ with $25 \%$-oxygen-content air. Although $\mathrm{NO}_{\mathrm{x}}$ emissions increased significantly, both for engine-out and catalytic converter-out emissions, we anticipate that they can be ameliorated in the near future with new control technologies. The automotive industry currently is developing exhaust-gas control technologies for an oxidizing environment; these technologies should reduce $\mathrm{NO}_{\mathrm{x}}$ emissions more efficiently in vehicles that use oxygen-enriched intake air. On the basis of estimates made from current data, several production vehicles that had low $\mathrm{NO}_{\mathrm{x}}$ emissions could meet the 2004 Tier II emissions standards with $25 \%$ oxygen-content air. The results indicate that adding oxygen to the intake air, instead of to the fuel (as in oxygenated gasoline), can achieve the same emissions reduction goal.
\end{abstract}

\section{INTRODUCTION}

The potential merits of oxygen enrichment in the intake air of spark-ignition engines are still being contested today. ${ }^{1-3}$ The most recent Japanese study ${ }^{3}$ showed an increase in 
thermal efficiency and a decrease in exhaust emissions of unburned hydrocarbons and carbon monoxide, whereas a General Motors report from $1971^{1}$ had shown decreases in thermal efficiency and decreases in unburned hydrocarbon and carbon monoxide emissions. However, both studies reported a substantial increase in $\mathrm{NO}_{\mathrm{x}}$ emissions.

The primary objective of this study was not to resolve the differences in fuel economy, but to determine if a polymeric-membrane oxygen-enrichment system could be readily retrofitted to a vehicle powered by a spark-ignition engine to produce reasonable performance with reduced emissions. Because most vehicles are fitted with three-way catalytic converters, which only work in a reducing environment, this experiment also showed whether this technique would have major impact on converter performance.

Another objective of this study was to determine if the oxygen-enrichment process would change some of the many hydrocarbon oxidation processes in the combustion chamber and the numerous catalytic hydrocarbon reactions in the converter and, consequently, modify the composition of exhaust hydrocarbons. In addition, the amount of benzene, 1,3-butadiene, formaldehyde, and acetaldehyde in the exhaust emissions was measured. [These constitute four out of the five air pollutants designated as toxic by the 1990 Clean Air Act (CAA).]

In this experimental study, intake-oxygen contents of 21,25 , and $28 \%$ were used in a production Chevrolet Lumina for emissions testing under the Standard Federal Test Procedure (FTP), 40 Code of Federal Regulations (CFR), Part 86. Both the engine-out emissions and the catalytic converter-out emissions were measured, and the distribution of hydrocarbon species were measured by means of gas chromatography.

Engine out emissions were emissions that came directly out of the engine (with the converter removed). Catalytic converter out emissions were emissions that came out of the catalytic converter (three-way catalytic was attached to the engine). All emission test results were compared with normal air (21\% oxygen). 


\section{EXPERIMENTAL SETUP AND TEST PROCEDURES}

\subsection{BACKGROUND}

To perform the experiment, an oxygen-enrichment system was designed and fabricated. The vehicle chosen, because of its popularity, was a 3.1-L Chevrolet Lumina, model year 1990. A variable-fuel version (VFV) of this vehicle is scheduled to be used for a subsequent, alternative-fuel study using oxygen enrichment. The tests were performed at the AutoResearch Laboratory in Harvey, Illinois.

\subsection{OXYGEN-ENRICHMENT SYSTEM}

The experimental setup was made up of the air-handling and the oxygen-supply systems, as shown in Figure 2.1. The air-handling system consisted of a plenum and a blower (300 standard $\mathrm{ft}^{3} / \mathrm{min}^{*}$ ) that continuously provided the plenum with excess air. The vehicle drew the intake air as required, and the excess air was purged. This system was designed to handle ambient air (21\% oxygen) and up to $30 \%$ oxygen-enriched air.

The oxygen-supply system consisted of 12 compressed-oxygen cylinders containing about twice the amount of oxygen required for one FTP emissions test. The outlet pressure of the oxygen cylinders was controlled by a two-stage manual regulator. The oxygen flowed through two liquid-oxygen vaporizers and an air-to-air heat exchanger to bring the oxygen to room temperature. The heated air was then fed into the air-handling system immediately before the blower inlet to ensure thorough mixing with ambient air. The well-mixed oxygenenriched air was uniform in both temperature and oxygen concentration when it reached the plenum. The oxygen flow rate was controlled manually by means of a valve after the heat exchanger.

Before the start of the test, the blower was turned on, and the oxygen control valves were opened and controlled to provide a desired oxygen content at the plenum. Once the system stabilized, the emissions test or conditioning cycle would start. Normally, this start-up process would take about 3-5 $\mathrm{min}$.

To demonstrate that the oxygen-enriched-air-handling system would function properly during the FTP emissions test cycle at the four different oxygen contents, the vehicle was driven through the first two hills of the driving cycle. As shown in Figure 2.2, the oxygen contents of $21,25,28$, and $30 \%$ (measured at the plenum) remained fairly stable through these driving sections. (Note: The 30\% oxygen concentration was not used in the actual FTP emissions test.)

* $s c f m=$ standard cubic feet per minute, $\mathrm{ft}^{3} / \mathrm{min}$. 


\section{Component Name}

1 Oxygen supply

2 Oxygen pressure regulator

3 Oxygen safety-shutoff solenoid

4 Oxygen temperature control

5 Oxygen flow-control valve

6 300-scfm blower outlet

7 Enriched air plenum
(7)

surplus

to vehicle 


\section{Plenum Oxygen Concentrations During First 2 Hills of Constant Volume Sampling Cycle at 4 Levels of Oxygen}

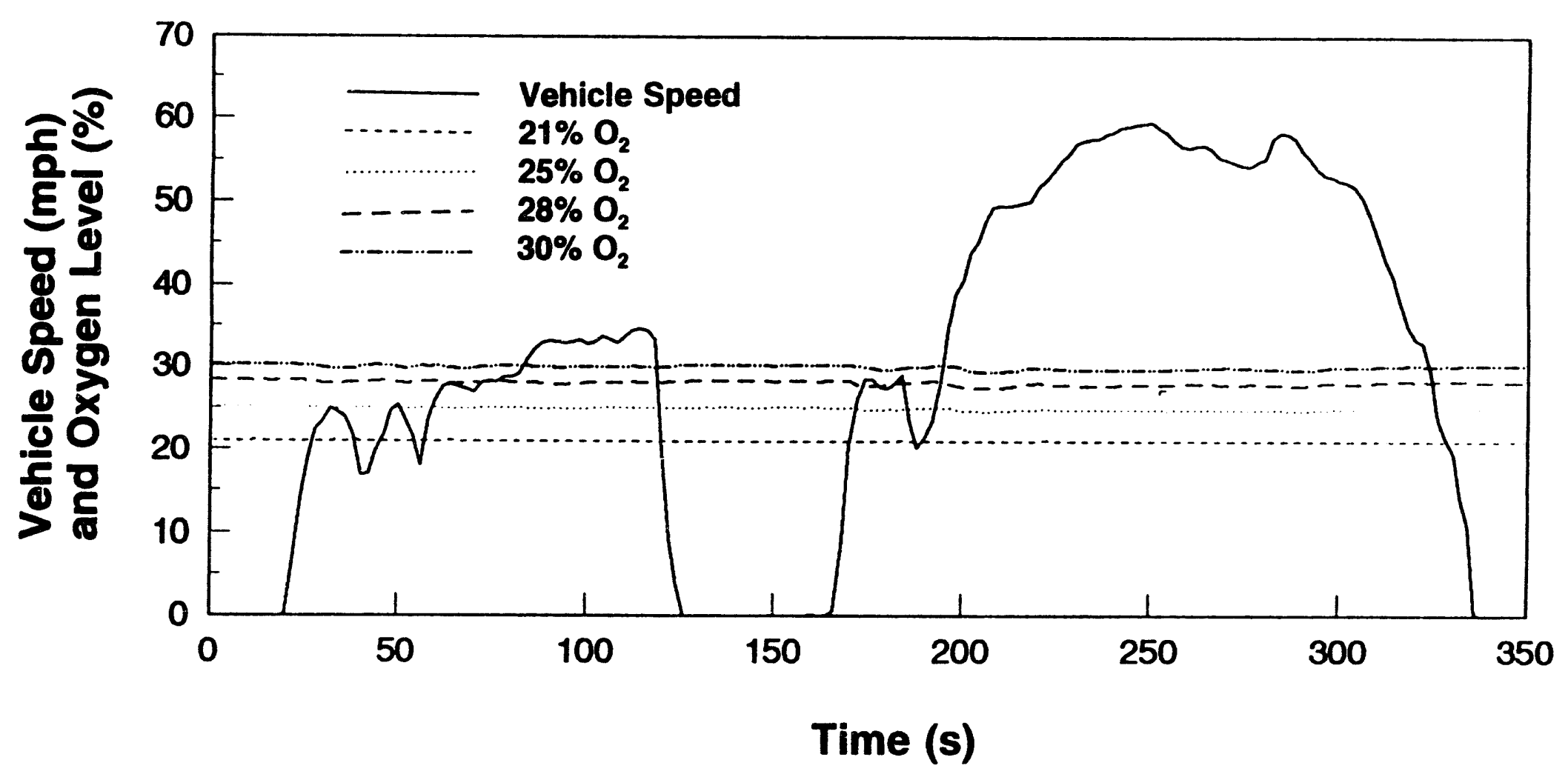

FIGURE 2.2 Stability of Oxygen-Enrichment System 
The compressed oxygen from the cylinders had the potential of over-pressurizing the air-handling system and feeding the vehicle with excessive oxygen. Therefore, three manually operated emergency shutoff switches were installed, one each in the control panel of the enriched-air-handling system, the emissions lab, and the vehicle.

\subsection{VEHICLE MODIFICATIONS}

The positive crankcase ventilation (PCV) and the evaporative emissions control (EEC) system on the 3.1-L Chevrolet Lumina were modified for this experiment. To avoid drawing the oxygen-enriched air through the engine crankcase, the PCV was short-circuited. A PCV valve was installed on the downstream side of the air-filter housing and was connected to the PCV port on the intake manifold, bypassing the crankcase. The crankcase was then vented to the exhaust system of the test cell.

The EEC system was modified to bypass the carbon canister. The purge line from the canister to the engine was disconnected at the canister and relocated to a port on the air filter housing. During oxygen-enriched-air operation, this modification would cause the engine to draw only the oxygen-enriched air (instead of the ambient air and fuel vapors) when the canister purge solenoid was activated. The fuel-tank vapor line was connected to a remote canister located at the rear of the vehicle. This line could be easily changed when it became loaded with fuel vapor.

For the engine-out emissions tests, the catalytic converter was removed and replaced by a piece of exhaust pipe. The pressure drop across the catalytic converter, however, was not simulated. For the catalytic converter-out emissions tests, the catalytic converter (with about 7,000 mi under normal driving conditions) was reinstalled.

\subsection{FTP EMISSIONS TEST PROCEDURES}

The vehicle was conditioned for testing by driving a single LA4 cycle (Los Angeles driving cycle \#4) while operating at the oxygen content to be tested. Following a 12-h minimum soak period $\left(68-86^{\circ} \mathrm{F}\right)$, vehicle exhaust emissions were measured per the FTP specified in 40 CFR, Part 86 . Subsequent duplicate tests were separated by a $12-\mathrm{h}$ minimum soak period with no reconditioning. The diurnal heat-build portion of the FTP was not performed because of the modifications made to the EEC system of the vehicle.

Tests were made in three phases: cold phase, stabilized phase, and hot phase. Three different oxygen percentages were used: 21,25 , and $28 \%$. Air bags were used to collect the exhaust emissions for each of the three phases. A separate bag was used for each oxygen enrichment $\mathrm{mix}(21,25$, and $28 \%)$ at each phase. The air bags were labeled as follows:

- Bag 1 (Cold Phase). Includes separate bags for 21, 25, and 28\% rxygen enrichment. 
- Bag 2 (Stabilized Phase). Includes separate bags for 21, 25, and $28 \%$ oxygen enrichment.

- Bag 3 (Hot Phase). Includes separate bags for 21,25 , and $28 \%$ oxygen enrichment.

\subsection{HYDROCARBON SPECIATION TECHNIQUES}

Hydrocarbon speciation was performed by analyzing a portion of the diluted exhaust sample by means of gas chromatography. One sample was analyzed from each of the three bags of exhaust gas collected for the three phases of the FTP emissions test.Aldehyde levels were measured by passing the diluted exhaust sample through silica gel cartridges impregnated with 2,4-dinitrophenylhydrazine. One cartridge was used for each of the three bags. 


\section{EXPERIMENTAL RESULTS AND DISCUSSION}

\subsection{VEHICLE PERFORMANCE}

The vehicle ran smoothly with the oxygen-enriched intake air at increasing oxygen content until this content reached $30 \%$ by volume; at $30 \%$ oxygen, the engine began to knock. Even though the test facility was very noisy, because of the oxygen rushing out of the cylinders, the hammering noise coming from the engine was very noticeable. At and below an oxygen content of $28 \%$, the vehicle had excellent response, and the driver had to back off the throttle to keep the required speed for the FTP emissions tests.

At an oxygen content of $28 \%$, there was no audible knocking throughout the FTP emissions test; however, there was a constant need for timing retardation during acceleration. Timing retardation increased from about 5 crank angle (CA) for $0-30 \mathrm{mph}$ (modest acceleration) to about $11 \mathrm{CA}$ for 0-55 mph (hard acceleration). The output from the knock sensor, in combination with the timing retard record, provided a fair indication of the knocking condition in these tests. There seemed to be no timing retardation required during any steady-state speed part of the test cycle. For the whole cycle, the amount of throttle never exceeded 24\%; normally, less than $10 \%$ was required. At an oxygen content of $25 \%$ the driver noticed little change in vehicle performance, except for smoother operation compared with normal-air ( $21 \%$ oxygen) operation.

Output from the knock sensor was fed to the vehicle's on-board computer to activate spark timing retardation. Evidently, the maximum allowable retardation in spark timing for this vehicle was not enough to alleviate the knocking problem when the oxygen content was higher than $28 \%$. The knocking at high oxygen content was probably due to an increase in flame speed. This caused the burned mixture to expand rapidly; and when the gases compressed the unburned mixture, low-temperature chemical reactions (auto-ignition) resulted and led to a knocking condition. The ${ }^{\text {act }}$ that the mixture had the oxygen-enriched air could also have increased the knocking tendency. However, at an oxygen content of $25 \%$, flame speed was not increased by much, and the unburned gas mixture would not have been compressed fast enough to initiate such an auto-ignition condition.

\subsection{ENGINE-OUT EMISSIONS}

All emissions data presented are the averages of three separate FTP emissions tests (cold, stabilized, and hot phases) under identical operating conditions and procedures.

Almost 200 hydrocarbons were identified in the engine-out emissions, but only the most significant species were selected for analysis here. To facilitate the discussion these species were grouped into aldehydes, olefins, aromatics, and paraffins.

Engine-out emission testing was done for the following emissions: carbon monoxide (CO), hydrocarbons, aldehydes, olefins, aromatic compounds, paraffin, ozone, and $\mathrm{NO}_{\mathrm{x}}$. Tests 
were run at $21 \%$ oxygen (normal air) and at $25 \%$ and $28 \%$ oxygen enrichment for each of the three phases. Emissions were collected in bags as follows:

- Bag 1 (Cold Phase)

- Bag 2 (Stabilized Phase)

- Bag 3 (Hot Phase)

\subsubsection{Carbon Monoxide Emission Testing}

Carbon monoxide emissions were reduced by almost one-half at the cold phase of the FTP (bag one); there were few changes at the stabilized and hot phases (bags two and three) when the oxygen content of the air was $28 \%$. These results and the weighted results are shown in Figure 3.1 .

The reduction in $\mathrm{CO}$ emissions was caused mainly by the higher oxygen content and partially by the leaner-than-normal air combustion, as indicated by the higher oxygen concentration in the exhaust gas, especially during the first two to three minutes of the cold phase. (Note: the total cold phase runs for 505 seconds.) This leaner condition resulted from the inability of the vehicle's air/fuel management system to handle the high-oxygen-content air. Nevertheless, these results show that the engine was capable of burning leaner (around $10-20 \%$ less fuel), without misfiring, with the oxygen-enriched air.
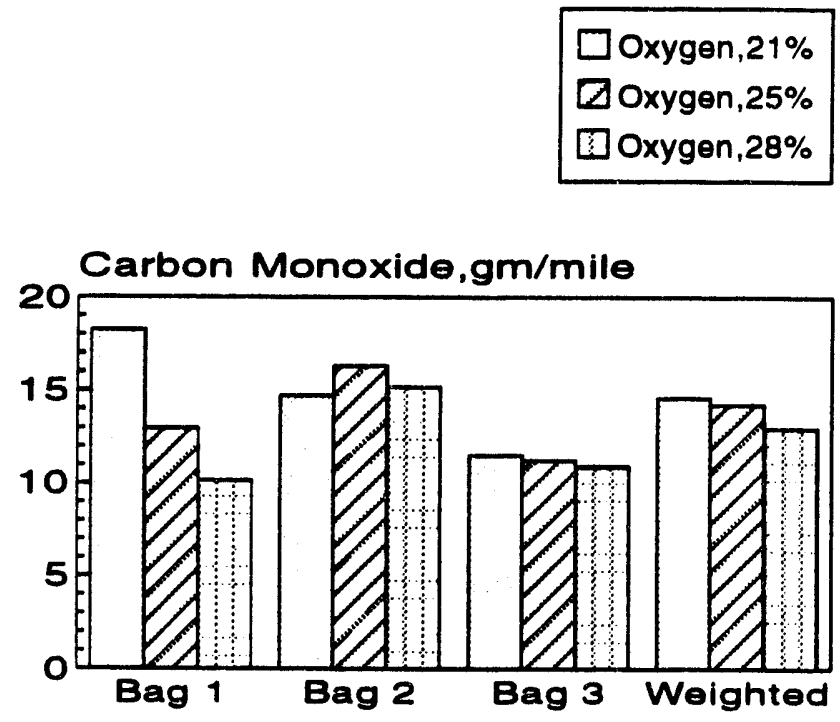

FIGURE 3.1 Effects of Oxygen-Enriched Intake Air on Engine-Out CO Emissions 


\subsubsection{Hydrocarbon Emission Testing}

Total FTP hydrocarbon emissions were reduced by one-half to two-thirds in all three bags at oxygen contents of 25 and 28\%, respectively, as shown in Figure 3.2. Increasing the oxygen content from 25 to $28 \%$ yielded only minimal reductions.

\subsubsection{Aldehyde Emission Testing}

Aldehydes are important for ozone formation; they have an offensive smell in addition to their harmful health effects. Both formaldehyde and acetaldehyde emissions (1990 CAA toxic air pollutants) are extremely high with $\mathrm{OH}$-containing fuels, such as methanol and ethanol, and C-O-C-containing species, such as ethers. The aldehyde emission problem is the major obstacle to the widespread use of alcohol fuels in spark-ignition engines. Even the most up-to-date catalytic converters have not solved this problem, according to the most recent data collected by the National Renewable Energy Laboratory (NREL). ${ }^{4}$

The use of oxygen-enriched air significantly decreased aldehyde emissions, as shown in Figure 3.3. The mechanisms for the reduction are not clear, but the results seem to indicate that the higher concentration of oxygen in the combustion chamber did not favor the formation of $\mathrm{OH}$ and $\mathrm{C}=\mathrm{O}$, even if more than enough hydrogen and oxygen were available. In the case of alcohols and ethers, the chemically-bonded oxygen atoms are in either $\mathrm{C}-\mathrm{OH}$ or C-O-C bonds, which may well serve as the building blocks for the aldehydes containing both the $\mathrm{C}-\mathrm{OH}$ and $\mathrm{C}=\mathrm{O}$ bonds. Therefore, the oxygen-enrichment technique may be a better way to reduce carbon monoxide than oxygenated gasoline, which uses alcohols or ethers (such as MTBE and ETBE) to increase the oxygen content of gasoline.

\section{Hydrocarbons, gm/mile}

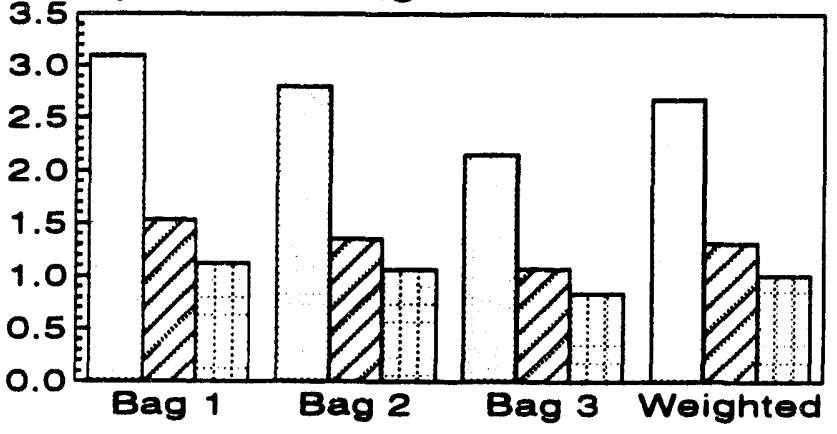

FIGURE 3.2 Effects of Oxygen-Enriched Intake Air on Engine-Out Hydrocarbon Emissions 
$\square$ oxygen, $21 \%$

Doxygen, $25 \%$

$\square$ Oxygen, $28 \%$
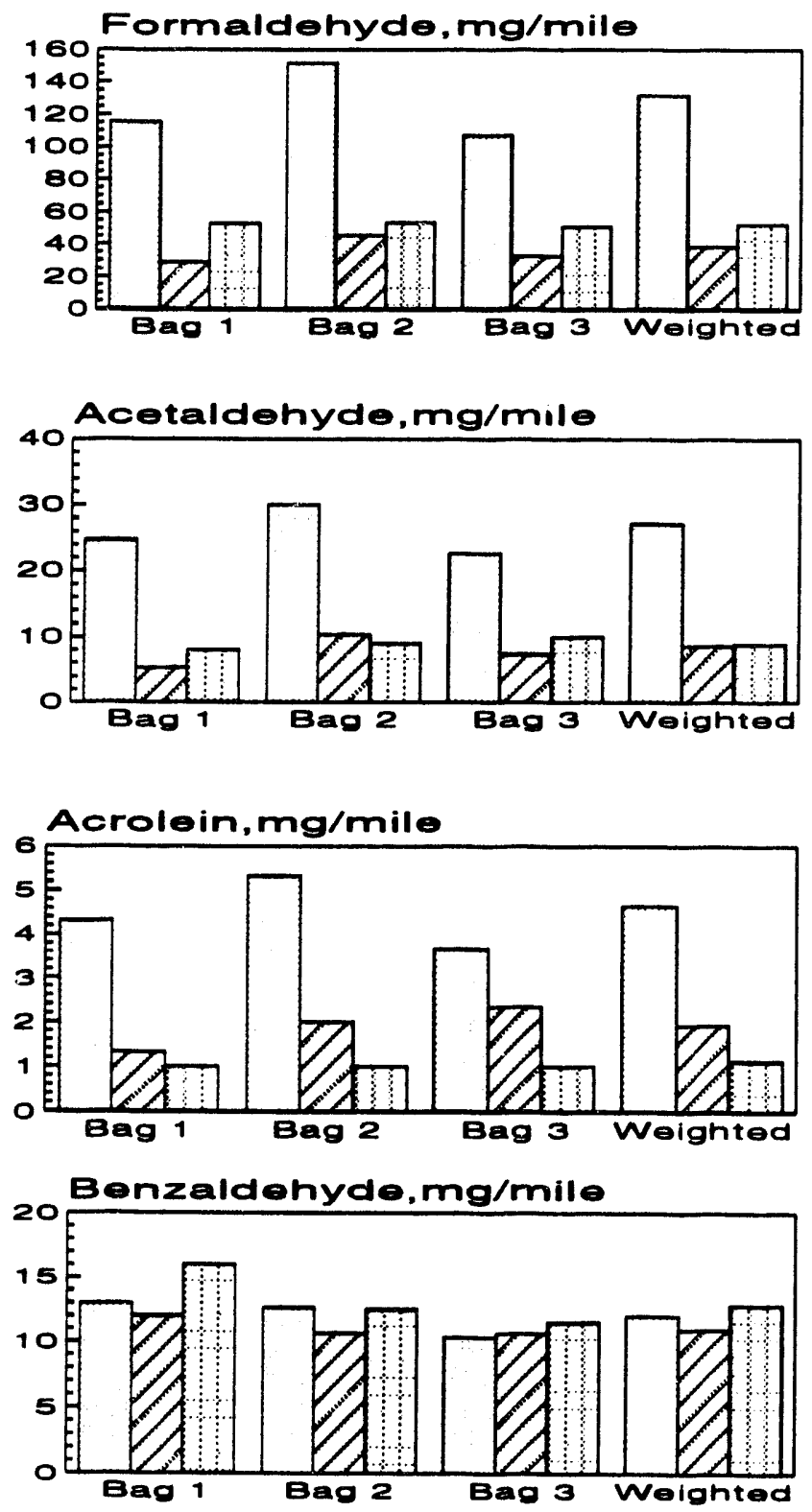

FIGURE 3.3 Effects of Oxygen-Enriched Intake Air on Engine-Out Aldehyde Emissions 
When the oxygen content was increased from 25 to $28 \%$, three out of four aldehydes showed slight increases in emissions. This significant trend was unique to the aldehydes. If aldehyde mechanisms are dictated by oxygen concentration, a further increase in oxygen concentration may have accelerated the formation reactions of the aldehydes. An analogy is the effects of oxygen in the formation and oxidation processes of particulates in combustion systems. Depending on the concentration of oxygen, oxygen can either be the particulates oxidizer or the catalyst for pyrolysis of hydrocarbons, leading to the formation of more particulates. 5

\subsubsection{Olefin Emission Testing}

Olefins are also significant contributors to smog and ozone, particularly in the five species depicted in Figure 3.4. In general, sur istantial reductions were obtained with the 25\%-oxygen-content air (compared with normal air combustion), but an additional 3\% oxygen did not yield any additional reductions. The species 1,3-butadiene, which has two double bonds and is a CAA air toxic pollutant, had the highest level of reduction among the olefins, at close to $80 \%$ when compared with normal air. This is a reasonable result, because the most reactive combustion by-products are most likely to react with the available oxygen when there are fewer nitrogen molecules to inhibit reaction.

\subsubsection{Aromatic Emission Testing}

In addition to benzene (a carcinogen), which is identified as a CAA toxic air pollutant, there were other aromatics that existed in significant amounts in the engine-out emissions. Again, such compounds were reduced drastically with the 25\%-oxygen-content air, compared with normal air. However, an additional 3\% oxygen increase had very little improvement, as shown in Figure 3.5. One of the shortcomings of the hydrocarbon speciation technique is that compounds containing more than 12 carbons cannot be identified. Therefore, several polycyclic aromatic compounds remained unidentified.

The harmful health effects of many polycyclic compounds have been reported in various medical studies. Their allowable emission levels from any combustion system will certainly be legislated as soon as reliable techniques become available to identify and measure these compounds. The future for oxygen enrichment in reducing these aromatics in engine-out emissions is promising.

\subsubsection{Paraffin Emission Testing}

The last group of hydrocarbon compounds is the paraffins, which are extremely difficult to convert into less harmful hydrocarbons, carbon dioxide, and water at the catalytic converter. Here, oxygen enrichment reduced most of the paraffins by more than $50 \%$ at the 

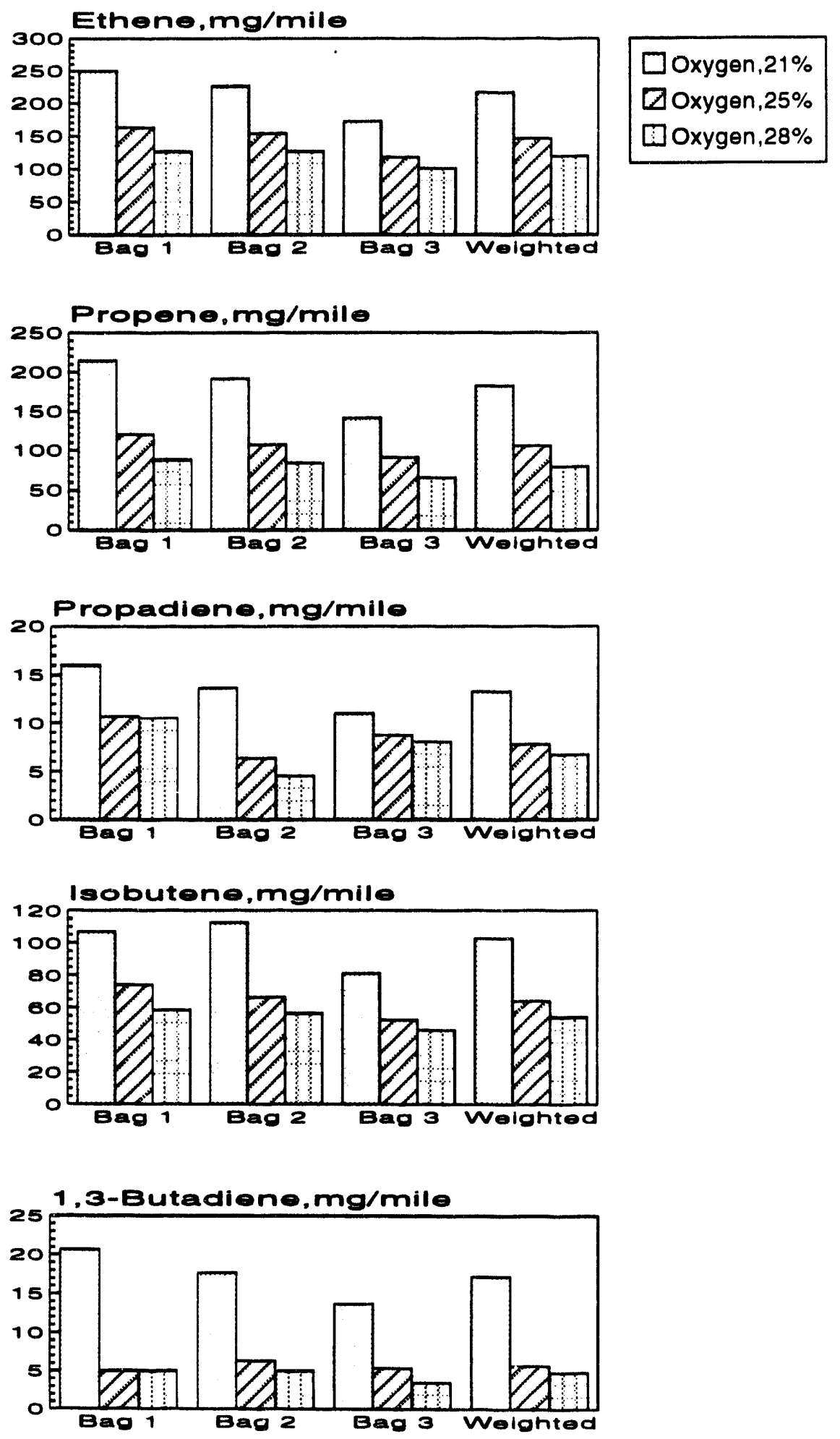

FIGURE 3.4 Effects of Oxygen-Enriched Intake Air on Engine-Out Olefin Emissions 

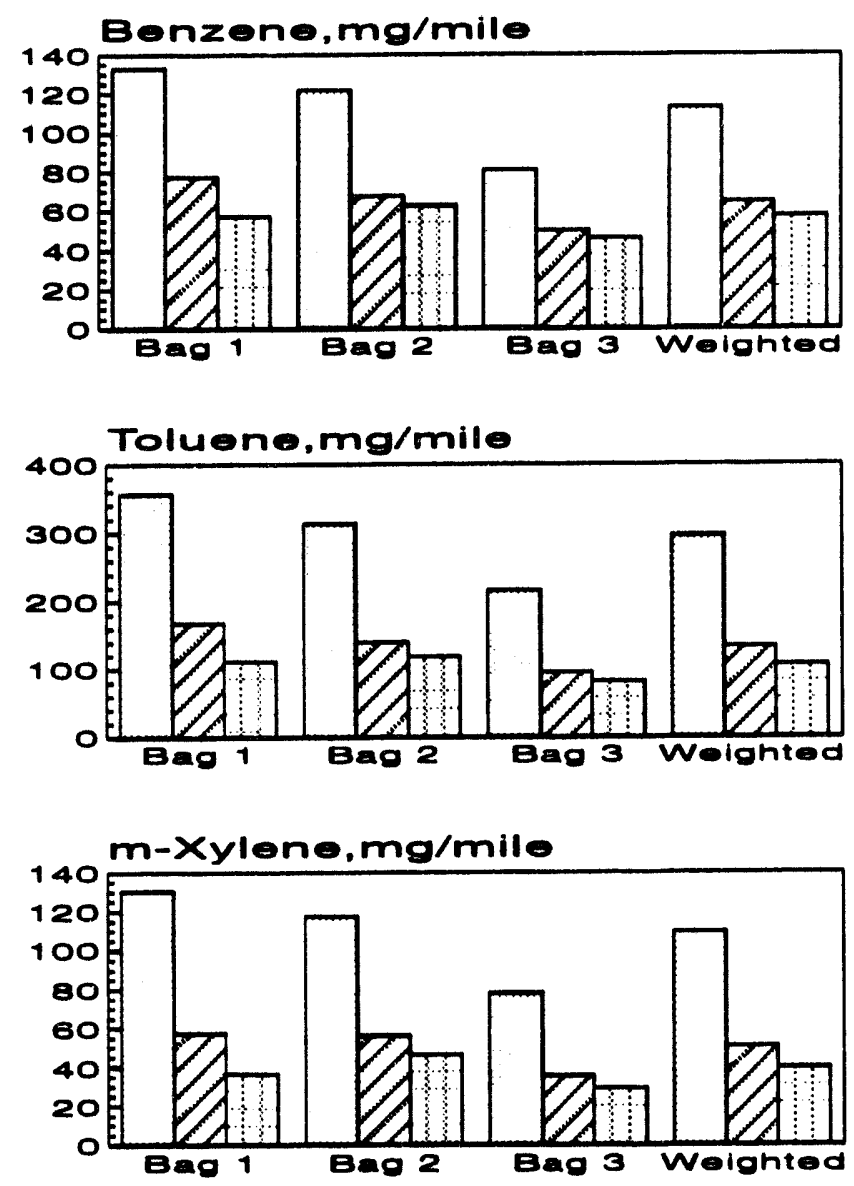

FIGURE 3.5 Effects of Oxygen-Enriched Intake Air on Engine-Out Aromatic Emissions

25\%-oxygen-content air, when compared with normal air. However, the reduction of methane was only about $20 \%$ (Figure 3.6 ) at the $25 \%$ oxygen level; at the $28 \%$ oxygen level, methane did not decrease significantly, primarily because methane is harder to break down than the other paraffins.

\subsubsection{Ozone Emission Testing}

The benefits of intake-air oxygen enrichment for the reduction of ozone had been investigated by means of the Carter maximum incremental reactivity (MIR) and the maximum ozone incremental reactivity (MOIR) factors. ${ }^{6}$ MIR represents an atmospheric condition that is low in hydrocarbons (HC) and has a low $\mathrm{HC} / \mathrm{NO}_{\mathbf{x}}$ ratio; ozone formation 

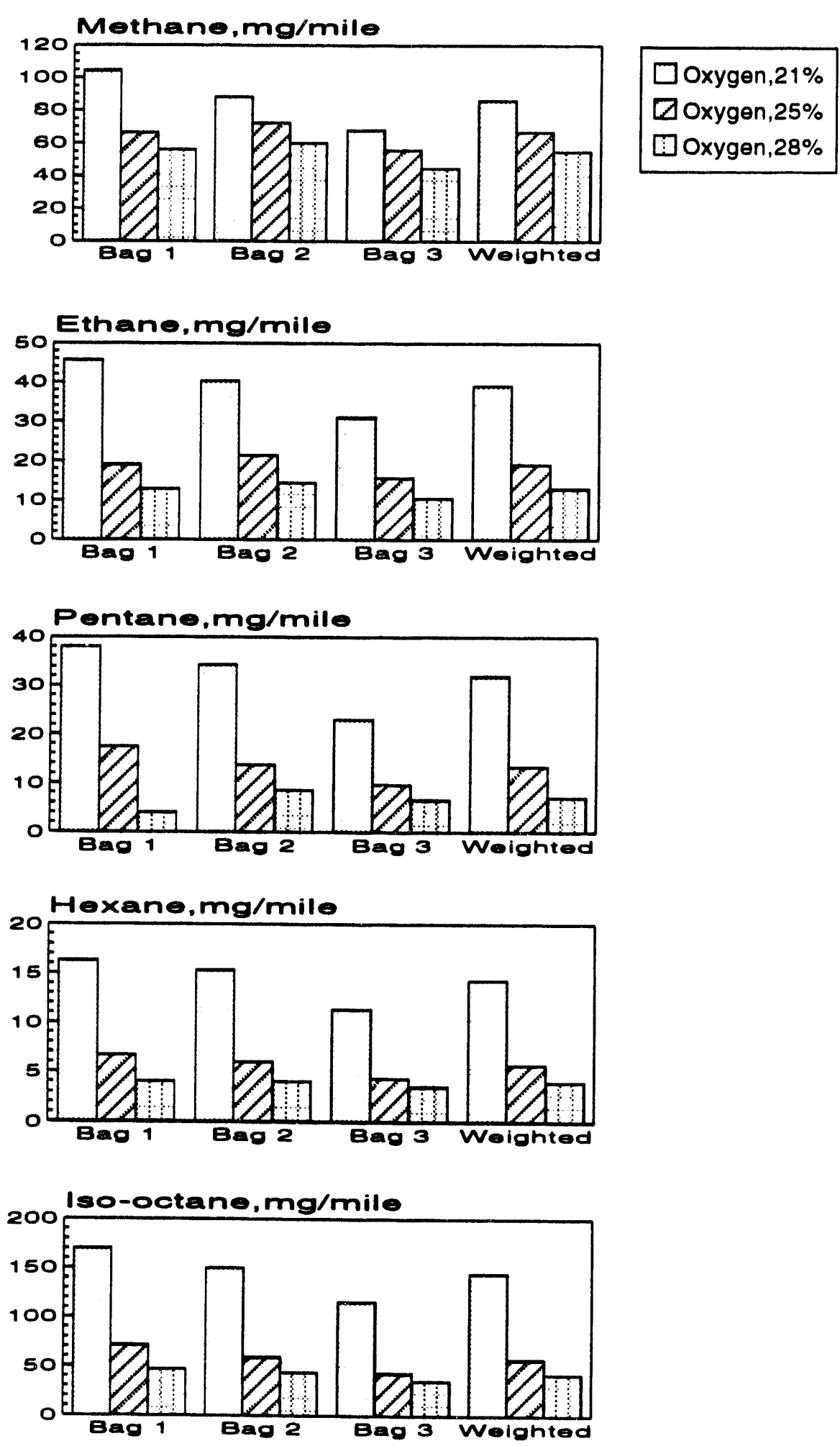

FIGURE 3.6 Effects of Oxygen-Enriched Intake Air on Engine-Out Paraffin Emissions 
is limited by the availability of hydrocarbons. MOIR similarly represents atmospheric conditions when (1) both hydrocarbons and $\mathrm{NO}_{\mathrm{x}}$ are important, (2) the $\mathrm{HC} / \mathrm{NO}_{\mathrm{x}}$ ratio is moderate, and (3) the total ozone formation is at a maximum. Because of the lack of understanding of atmospheric chemistry, there are uncertainties in both factors, so that these ozone estimates must be interpreted carefully. Because oxygen enrichment had changed the composition of the hydrocarbons in the engine-out emissions, the integrated effects of these individual hydrocarbons on ozone needs to be analyzed.

With the 25\%-oxygen-content air (Figure 3.8), there was an ozone reduction of approximately $50 \%$ in the three FTP bags and the weighted amount, when the MIR scale was used. Similarly, there was a $45 \%$ ozone reduction when the MOIR scale was used. With the 28\%-oxygen-content air (Figure 3.8), the weighted ozone was only further reduced slightly, except in FTP bag 1 where the reduction was almost twice that of either bag 2 or bag 3 .

\subsubsection{NO Emission Testing}

The results plotted in Figure 3.9 clearly show that $\mathrm{NO}_{\mathrm{x}}$ emissions were all increased between three and five times in the three bags with the oxygen-enriched air. A solution to this problem of high $\mathrm{NO}_{\mathrm{x}}$ emissions remains to be developed.
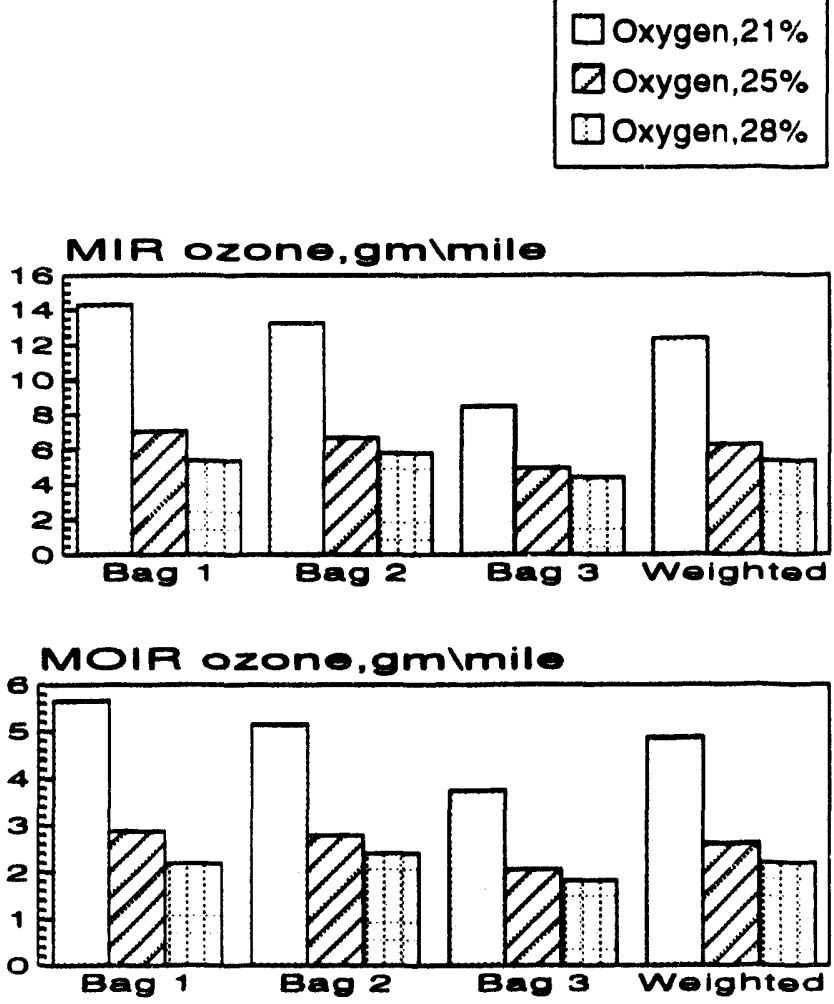

FIGURE 3.7 Effects of Oxygen-Enriched Intake Air on Engine-Out Ozone Emissions 


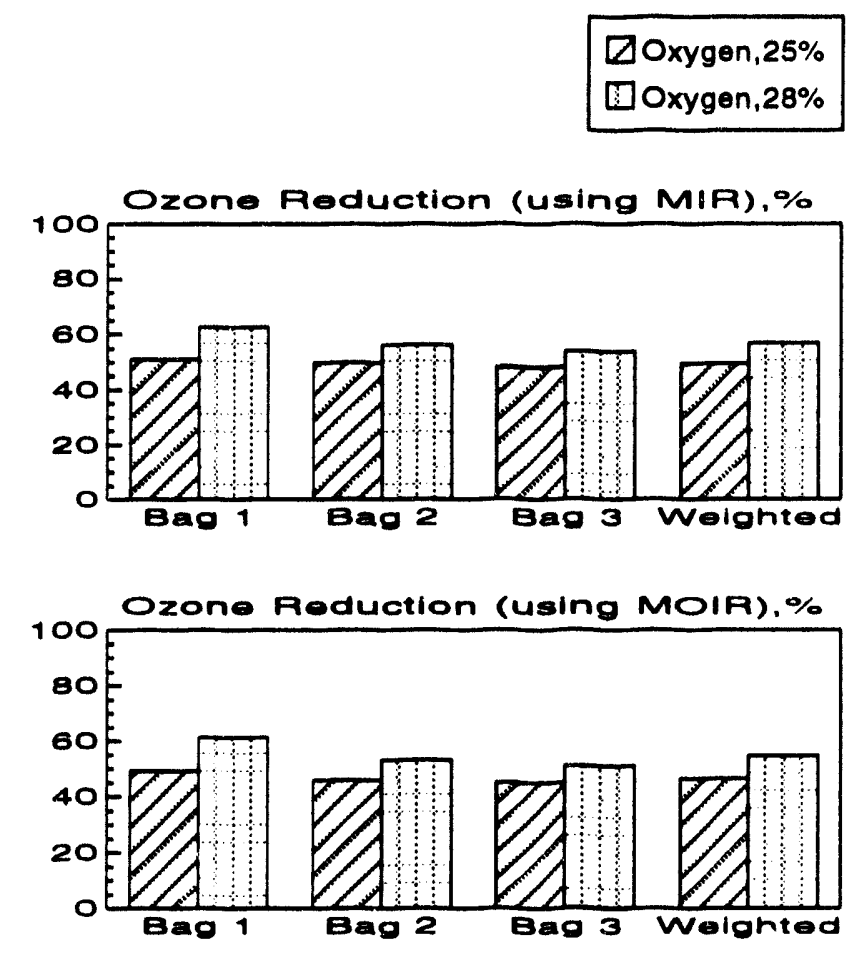

FIGURE 3.8 Effects of Oxygen-Enriched Intake Air on Engine-Out Ozone Reductions
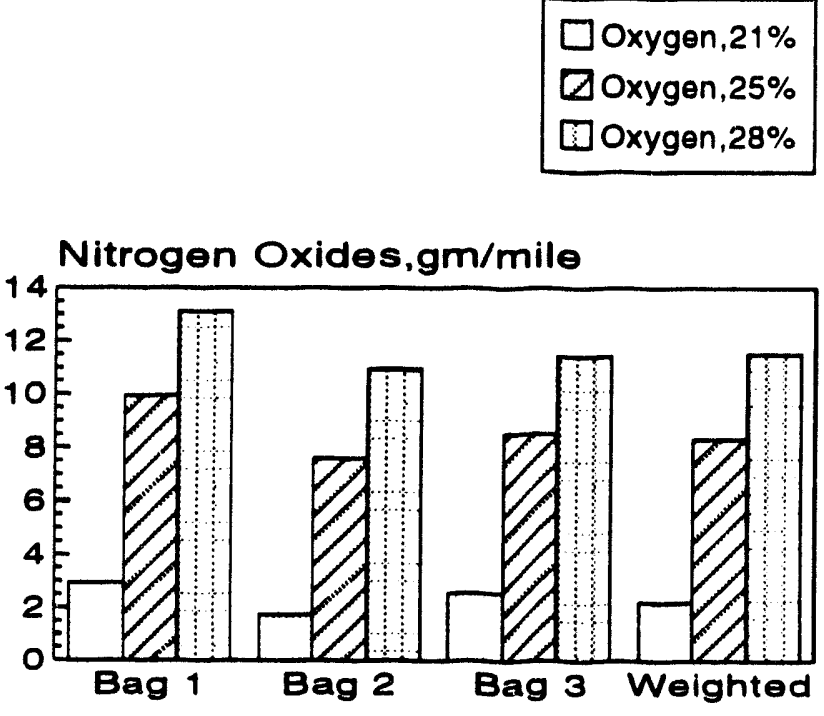

FTGURE 3.9 Effects of Oxygen-Enriched Intake Air on Engine-Out NO Emissions 


\subsubsection{Remarks}

The drastic reductions in hydrocarbon species in engine emissions and their subsequent ozone reductions are the result of two major factors associated with oxygen enrichment. First, on a weight basis, there is less of a gas mixture because there is a slight decrease in volumetric efficiency and there is less nitrogen than the normal air; therefore, there are fewer nitrogen molecules to be heated before and during combustion. The gas temperature increases and accelerates all reactions. Second, by having fewer nitrogen molecules, radicals can react with the hydrocarbons more quickly because there will be fewer nitrogen molecules in the way. Reaction rates in general are directly proportional to fruitful collision frequency among atoms, radicals, and molecules. Unfortunately, these two factors are also conducive to the generation of $\mathrm{NO}_{\mathbf{x}}$, especially when the gas temperature is higher than that in normal air combustion.

\subsection{CATALYTIC CONVERTER-OUT EMISSIONS}

The results reported here are the averages of values obtained in three separate FTP emissions tests performed under the same operating conditions and procedures. Both the carbon monoxide and hydrocarbon emissions were substantially reduced by the oxygen enrichment of the intake air. These emissions levels were even lower than the year 2004 (Tier II) light-duty-vehicle emissions standards ( $1.7 \mathrm{~g} \mathrm{CO} / \mathrm{mi}$ and $0.125 \mathrm{~g} \mathrm{HC} / \mathrm{mi})$, except for the $\mathrm{NO}_{\mathbf{x}}$ emissions.

Again, there were almost 200 hydrocarbons identified in the catalytic converter-out emissions, and only four groups of species (aldehyde, olefins, aromatic, and paraffins) that are significant to air pollution were selected for analysis.

Catalytic converter-out emission testing was done for the following emissions: carbon monoxide (CO), hydrocarbon, aldehyde, olefin, aromatic, paraffin, ozone, and $\mathrm{NO}_{\mathbf{x}}$. Tests were made at $21 \%$ oxygen (normal air) and at 25 and $28 \%$ oxygen enrichment for each of the three phases. Emissions were collected in bags as follows:

- Bag 1 (Cold Phase)

- Bag 2 (Stabilized Phase)

- Bag 3 (Hot Phase)

\subsubsection{Carbon Monoxide Emission Testing}

The catalytic converter had shown a significant increase in carbon monoxide conversion efficiency with oxygen enrichment, compared with vehicle operation with normal air (Figure 3.10). The greatest improvement (lower CO) was in the cold phase of the FTP (bag 1), during which the engine was running with the 25 and $28 \%$ oxygen air. Apparently, 
Oxygen, $21 \%$

D Oxygen, $25 \%$

Doxygen, $28 \%$

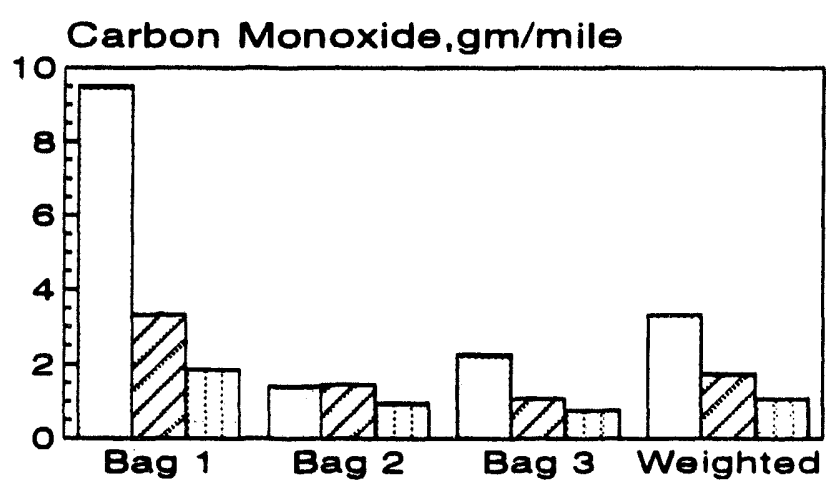

FIGURE 3.10 Effects of Oxygen-Enriched Intake Air on Catalytic Converter-Out CO Emissions

the additional oxygen in the converter simply provided more oxygen for the catalytic oxidation of the carbon monoxide, and the higher oxygen content also promoted the conversion reactions in the cold phase. In addition, there were substantially fewer hydrocarbons to compete with carbon monoxide for oxygen. There was no temperature increase in the engine exhaust with oxygen enrichment. However, the improvement (lower $\mathrm{CO}$ ) in the hot phase (bag 3) was due neither to the additional oxygen nor to the higher exhaust temperature, as indicated by the data on oxygen concentration and temperature of the gases entering the converter.

Two other major differences with oxygen enrichment were as follows: (1) much lower levels of hydrocarbons and (2) much higher $\mathrm{NO}_{x}$ levels coming into the catalytic converter. These two differences could, collectively or singularly, affect the carbon monoxide oxidation process. The exhaust-gas temperature at the converter was less than $1000^{\circ} \mathrm{F}$, well below the temperature $\left(1600^{\circ} \mathrm{F}\right)$ necessary for any significant water/gas reaction $\left(\mathrm{CO}+\mathrm{H}_{2} \mathrm{O}=\mathrm{CO}_{2}+\right.$ $\mathrm{H}_{2}$ ). The importance of this finding is that these data seem to confirm the current theory in catalysis that hydrocarbons play a very complex role in both the catalytic carbon monoxide oxidation and $\mathrm{NO}_{x}$ conversion processes.

\subsubsection{Hydrocarbon Emission Testing}

The total catalytic converter-out FTP hydrocarbons, as measured by a flame ionization detector (FID), showed drastic reductions in all three bags, again with oxygen enrichment (Figure 3.11). These improvements came mainly from the engine, not from the converter. By using both the engine-out and converter-out emissions data, the total 

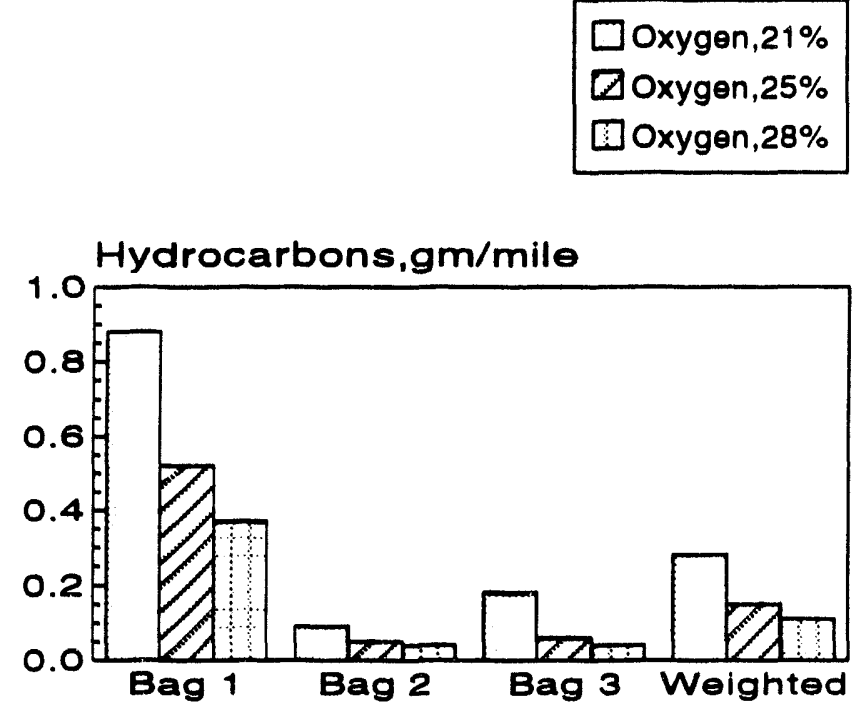

FIGURE 3.11 Effects of Oxygen-Enriched Intake Air on Catalytic Converter-Out Hydrocarbon Emissions

hydrocarbon conversion efficiencies were calculated for the converter. At the 25 and $28 \%$ oxygen levels, there was a slight decrease in conversion efficiency in both the cold and the stabilized phases and a marginal increase in the hot phase, when compared with the $21 \%$ oxygen (normal air). These small differences probably reflect experimental uncertainties.

\subsubsection{Aldehyde Emission Testing}

The converter-out aldehydes, as shown in Figure 3.12, were mostly from the cold phase, and the weighted emissions were less than $5 \mathrm{mg} / \mathrm{mi}$ at all oxygen levels. In comparing the aldehyde emissions of the engine-out with those of the converter-out, there was a drastic decrease in the cold-phase aldehyde-conversion efficiency when the $25 \%$-oxygen-content air was used instead of normal air (21\% oxygen). The average conversion efficiency for the four aldehydes dropped from $85 \%$ at normal air to $54 \%$ at $25 \%$-oxygen-content air. This efficiency returned to $85 \%$ when $28 \%$-oxygen-content air was used. This peculiarity points out the sensitivity of aldehyde reactions to a slightly different oxygen concentration in the system. In the first two to three minutes of FTP cold-phase operation with oxygen-enriched air, there was more oxygen in the converter than in the normal air operation, but this did not hold true for the rest of the test cycle. Further understanding of aldehyde oxidation chemistry is needed for converter development. 
$\square$ oxygen, $21 \%$

Doxygen, $25 \%$

Doxygen, $28 \%$
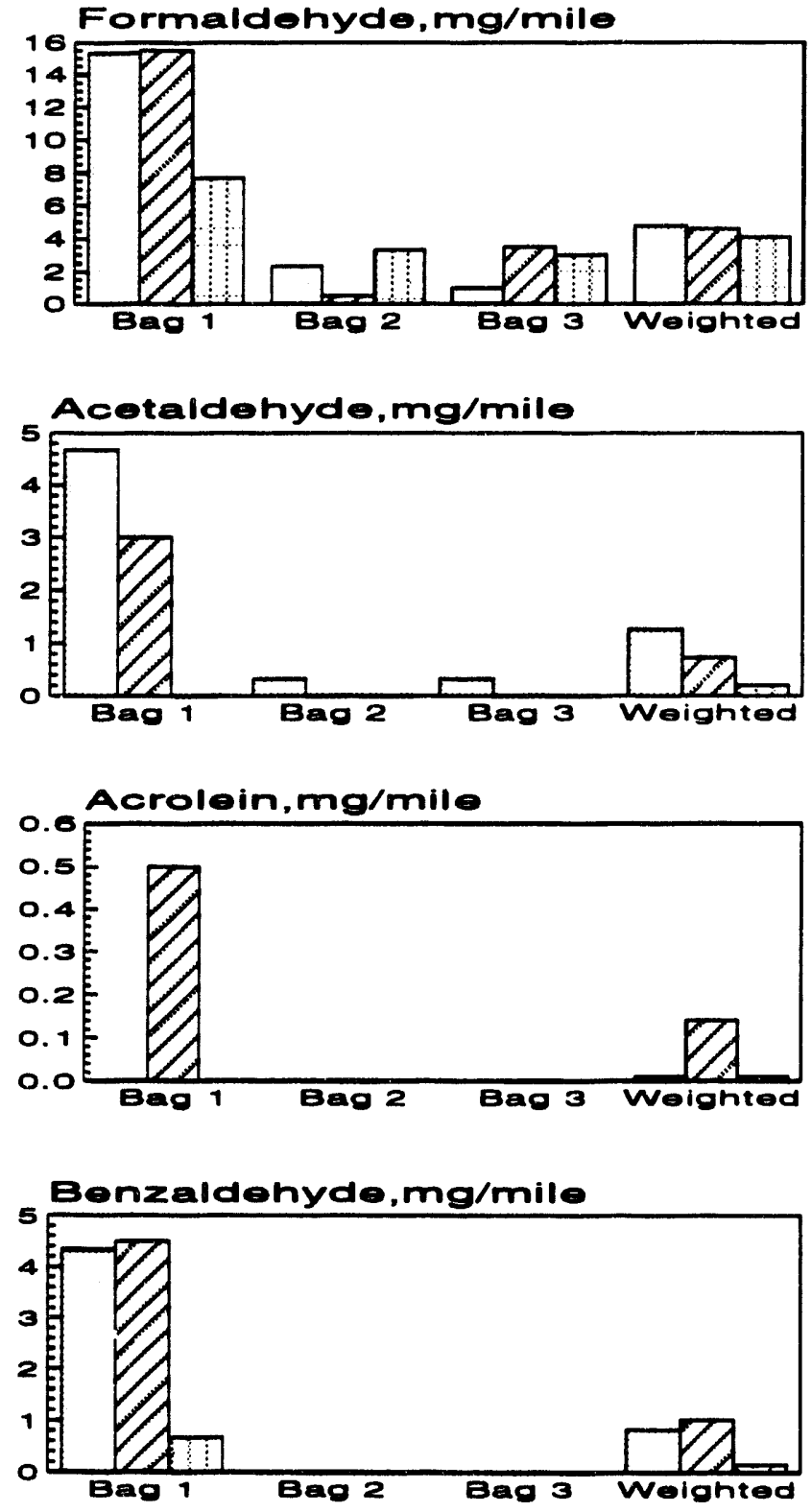

FIGURE 3.12 Effects of Oxygen-Enriched Intake Air on Catalytic Converter-Out Aldehyde Emissions 


\subsubsection{Olefin Emission Testing}

The catalytic converter-out reactive olefins were only significant in the cold phase of the FTP, as shown in Figure 3.13. The weighted emissions were all less than $15 \mathrm{mg} / \mathrm{mi}$, and they were approximately halved with the 25\%-oxygen-content air, as compared with normal air. An additional 3\% oxygen in intake air had very little effect on reducing the emissions. In the cold phase, there was a trend toward increasing conversion efficiency with increasing oxygen content on the basis of the average conversion efficiencies of the five olefins. However, the improvement amounted to only a few percent. 1,3-Butadiene showed the most reduction, from about $1 \mathrm{mg} / \mathrm{mi}$ at normal air to $0.08 \mathrm{mg} / \mathrm{mi}$ at $28 \%$-oxygen-content air.

\subsubsection{Aromatic Emission Testing}

The catalytic converter-out aromatics were most prominent in the cold phase of the FTP, as shown in Figure 3.14. The converter significantly reduced the levels of aromatics, while oxygen enrichment decreased the levels of weighted aromatics to the few-milligram-permile range in the standard and hot phases. Conversion efficiency improved slightly with the 25\%-oxygen-content air compared with normal air, but that improvement disappeared when oxygen content was increased to $28 \%$.

\subsubsection{Paraffin Emission Testing}

The paraffins were the most difficult to convert into other species and had the lowest conversion efficiencies of the four hydrocarbon groups discussed here. In general, the cold phase had the highest catalytic converter-out emissions of the three phases (Figure 3.15). The catalytic converter-out methane had the lowest level of reduction in comparison with the other paraffins, because of the low reduction in the engine and the modest converter efficiency in the cold phase with oxygen enrichment. This behavior of the converter with oxygen enrichment is similar to that in the engine, discussed earlier (Sub-section 3.2.6).

\subsubsection{Ozone Emission Testing}

In terms of the Carter MIR and MOIR factors, the 25\%-oxygen-content air reduced the FTP weighted ozone by about $60 \%$, while the $28 \%$-oxygen-content air yielded no further significant reductions (Figure 3.16). In the stabilized and hot-phases there were significant ozone reductions of between $12-23 \%$ when the oxygen content of the intake air was increased from 25 to 28\% (Figure 3.17). This result was just the opposite of that for the engine-out emissions (sub-section 3.2.7), which had the best ozone reduction in the cold phase (compared with the other two phases) when the oxygen content was increased by $3 \%$ from the $25 \%$ oxygen-content air. Further studies are needed to explain this significant trend. 


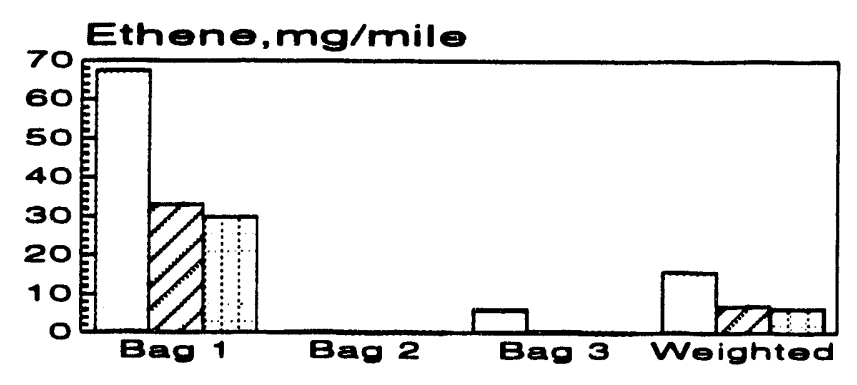

\begin{tabular}{|l|}
$\square$ oxygen,21\% \\
$\square$ oxygen,25\% \\
$\square$ Oxygen,28\%
\end{tabular}
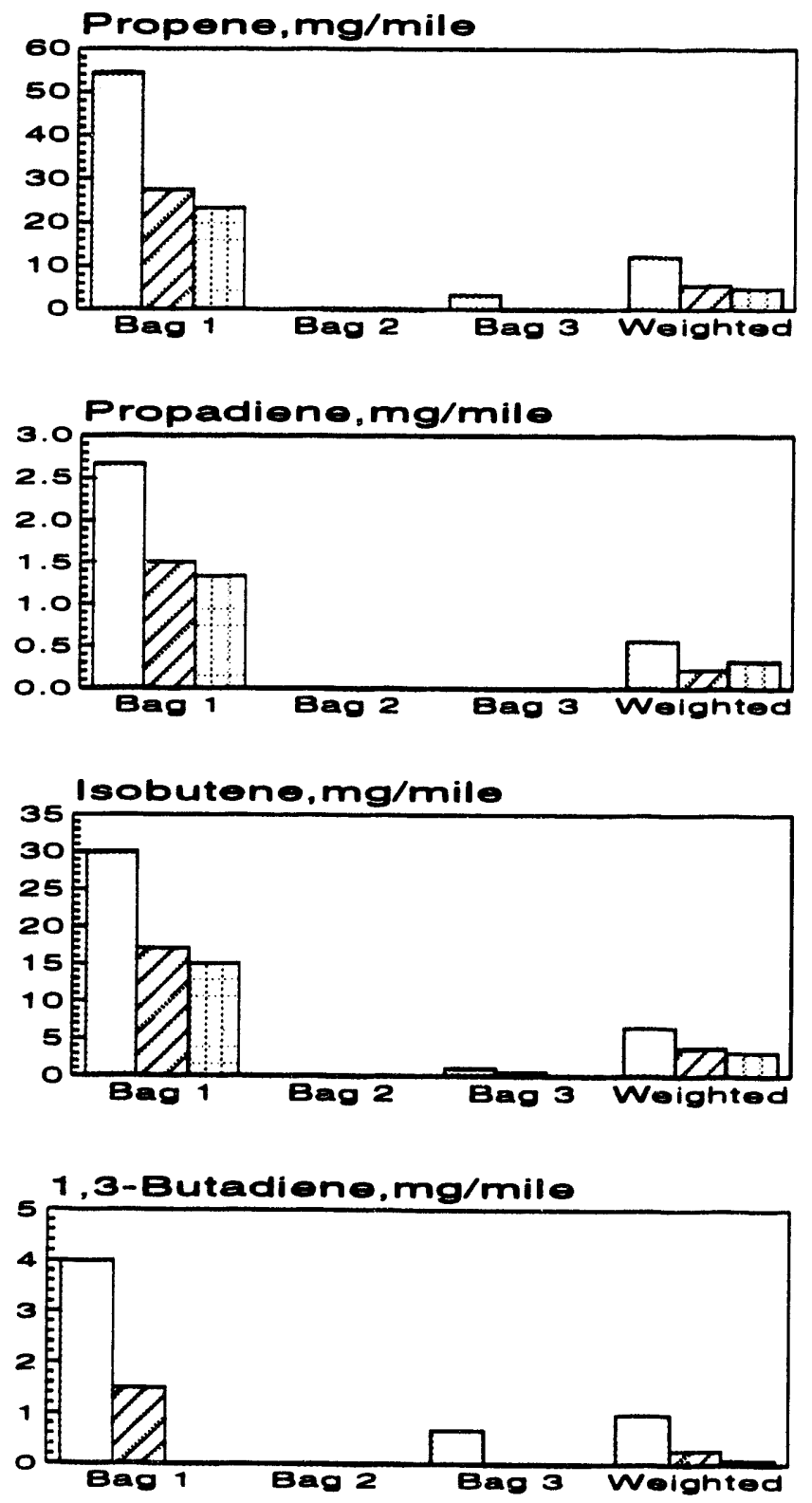

FIGURE 3.13 Effects of Oxygen-Enriched Intake Air on Catalytic Converter-Out Olefin Emissions 

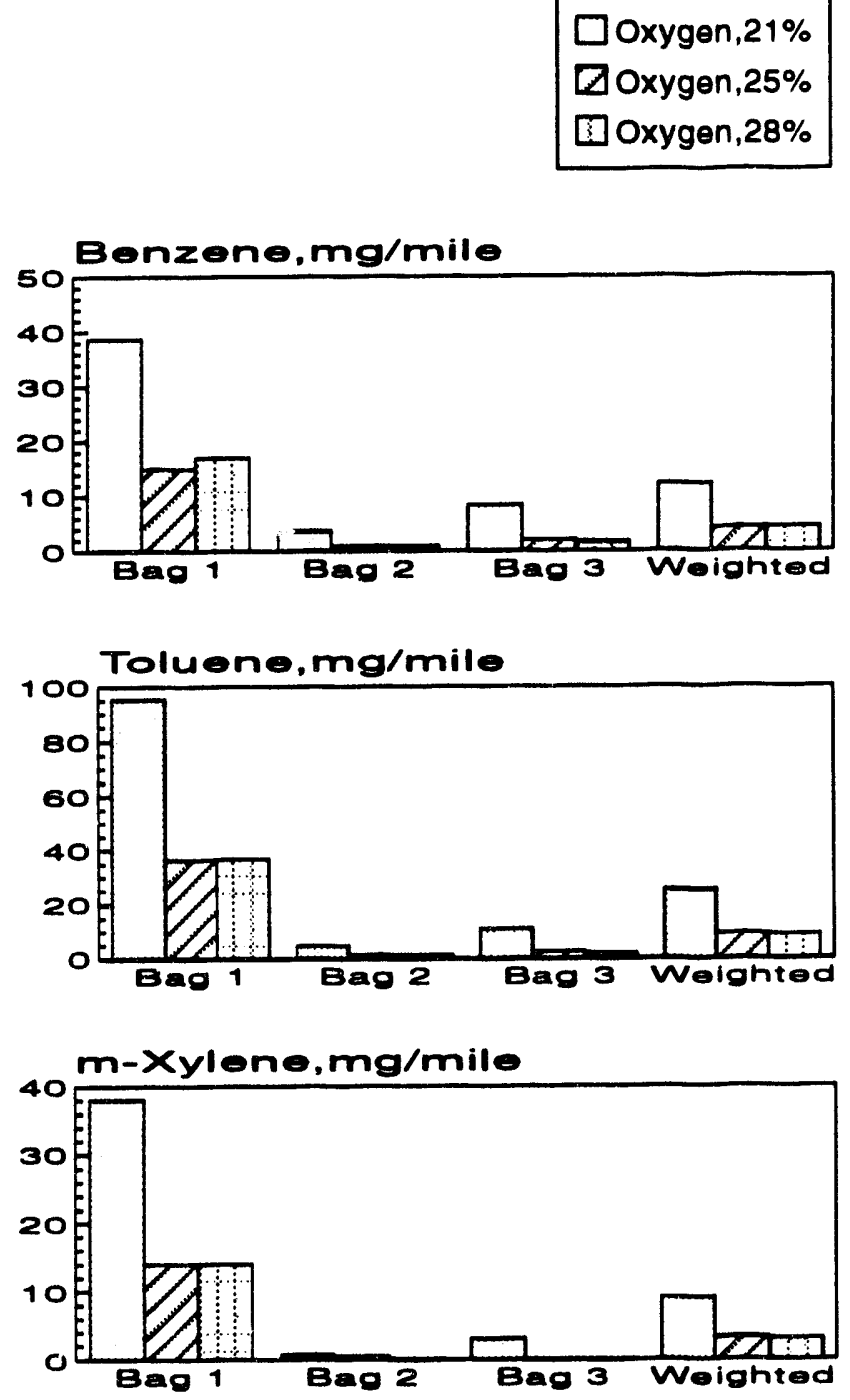

FIGURE 3.14 Effects of Oxygen-Enriched Intake Air on Catalytic Converter-Out Aromatic Emissions

\subsection{8 $\mathrm{NO}_{\mathrm{z}}$ Emission Testing}

The increase in $\mathrm{NO}_{\mathrm{x}}$ emissions (Figure 3.18) as a result of oxygen enrichment of the intake air was significant. To bring the $\mathrm{NO}_{x}$ emissions to the year 2004 (Tier II) standard of $0.2 \mathrm{~g} / \mathrm{mi}$, a catalytic converter efficiency in excess of $95 \%$ would be required for this vehicle. The catalytic converter had also shown a significant decrease in $\mathrm{NO}_{x}$ conversion efficiency as a result of oxygen enrichment of the intake air. The decrease was from $75 \%$ efficiency with normal air to about $39 \%$ efficiency with oxygen-enriched air. This degradation might be due to the oxidizing environment, the lower hydrocarbon concentration, and the order-ofmagnitude increase in $\mathrm{NO}_{\mathbf{x}}$ concentration because the catalytic converter was not designed to handle these very different conditions. 


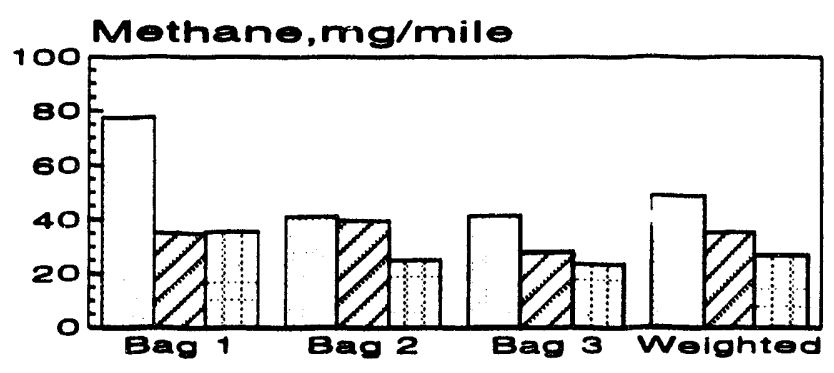

$\square$ oxygen, $21 \%$

Doxygen, $25 \%$

[Doxygen, $28 \%$
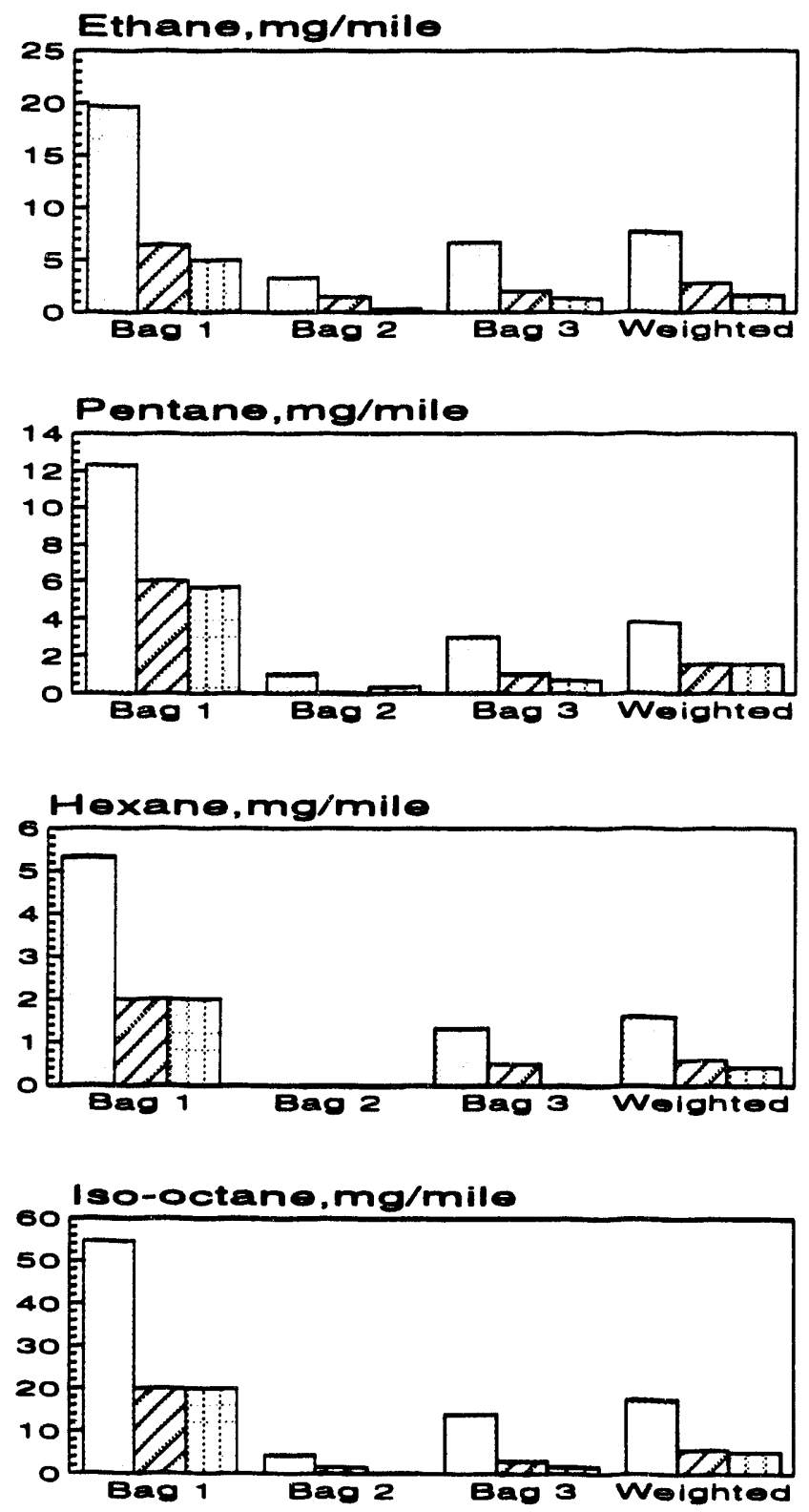

FIGURE 3.15 Effects of Oxygen-Enriched Intake Air on Catalytic Converter-Out

Paraffin Emissions 

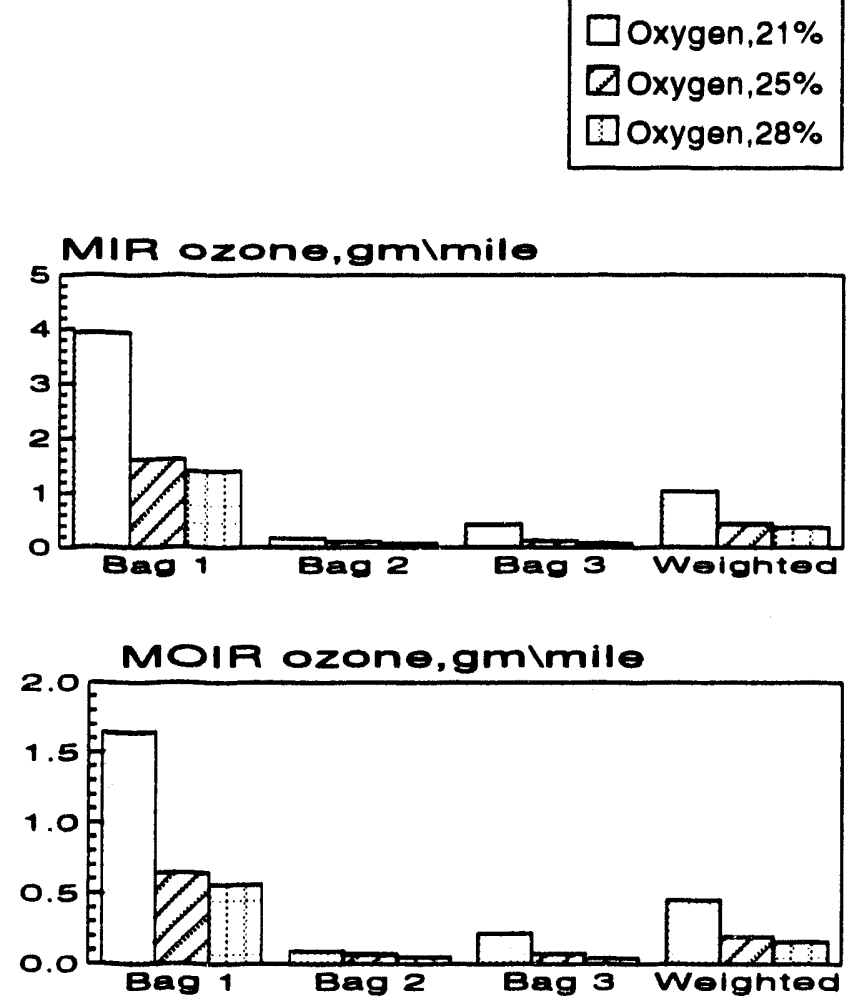

FIGURE 3.16 Effects of Oxygen-Enriched Intake Air on Catalytic Converter-Out Ozone Emissions

\subsubsection{Remarks}

The performance and emissions characteristics of the engine and the catalytic converter apparently did not measurably change after the series of oxygen enrichment experiments. However, these tests were brief, and the results reported here should not be extrapolated to predict the long-term effects of oxygen enrichment on the engine and on the catalytic converter.

\subsection{EMISSION CALCULATIONS USING OXYGEN ENRICHMENT RESULTS ON 1991 VEHICLES}

An assessment was also conducted by using the oxygen-enrichment results to determine whether the $\mathrm{NO}_{\mathrm{x}}$ emission problem could be overcome. The supposition was that if the vehicle had a low- $\mathrm{NO}_{\mathrm{x}}$-emission engine, but hydrocarbon and carbon monoxide emissions were relatively higher, this oxygen-enrichment technique would decrease the emissions of hydrocarbons and carbon monoxide and the emissions of $\mathrm{NO}_{\mathrm{x}}$ would increase, but the vehicle could still meet all the 2004 Tier II standards. 

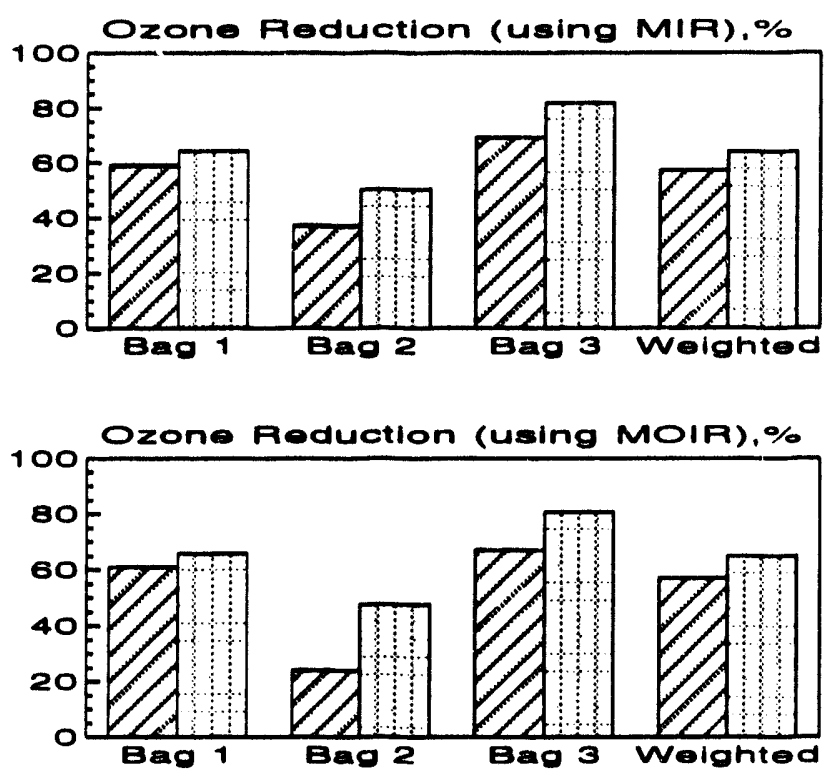

FIGURE 3.17 Effects of Oxygen-Enriched Intake Air on Catalytic Converter-Out Ozone Reductions

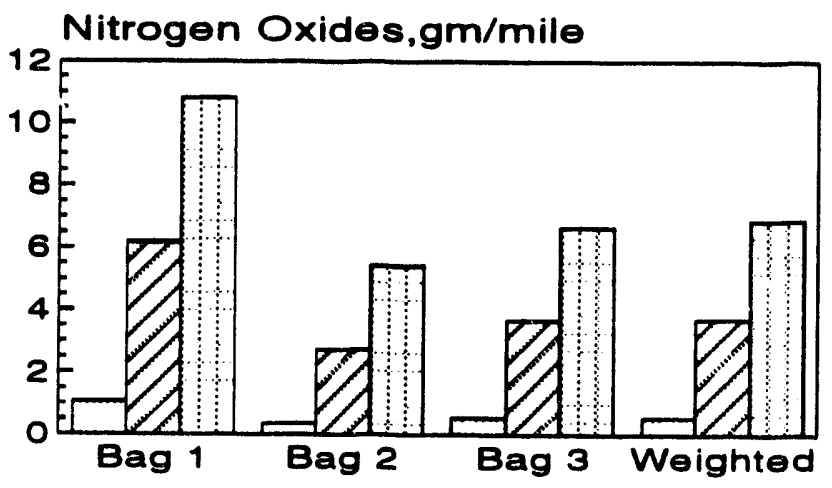

FIGURE 3.18 Effects of Oxygen-Enriched Intake Air on Catalytic Converter-Out $\mathrm{NO}_{\mathbf{x}}$ Emissions 
Light-duty-vehicle certification results ${ }^{7}$ were reviewed for the 1991 model year, and five vehicle models (Baretta, Capri, Le Baron, Corolla, and Cabriolet) were found to produce extremely low $\mathrm{NO}_{x}$ emissions. By using the three-way catalytic-converter conversion efficiencies for the carbon monoxide, hydrocarbon, and $\mathrm{NO}_{x}$ emissions (of the 1990 Lumina running under ambient air conditions), the investigators back-calculated the engine emissions of these 1991 vehicles using normal air. It was assumed that the 1991 vehicles would behave the same way as the 1990 Lumina at 25\%-oxygen-content air. The engine-out $\mathrm{NO}_{\mathrm{x}}$, hydrocarbon, and carbon monoxide emissions were calculated by using the 1990 Lumina engine data (i.e., at $25 \%$-oxygen-content air, hydrocarbons, were reduced by $51 \%$, carbon monoxide was reduced by $2 \%$, and $\mathrm{NO}_{\mathrm{x}}$ was increased by $377 \%$ ). These calculations showed the engine emissions would pass through the 1991 catalytic converter with $90 \%$ reduction efficiencies for carbon monoxide and hydrocarbons and an $80 \%$ reduction efficiency for $\mathrm{NO}_{\mathrm{x}}$. The simulated, FTP-weighted emissions are shown in Figure 3.19.

Both hydrocarbon and carbon monoxide emissions were below the year 2004 Tier II standards for all five vehicles, and three vehicles had $\mathrm{NO}_{x}$ emissions lower than the standard. This simple extrapolation showed that $\mathrm{NO}_{\mathrm{x}}$ emissions would be a problem in most vehicles, but the problem would be surmountable, provided that the catalytic converter could perform more efficiently under an oxidizing environment. The recently developed catalytic converters for lean-burn engines (spark ignition) can certainly benefit the oxygen-enrichment technology. 


\section{$\square$ Baretta $\square$ Capri 且LeBaron $\square$ Corolla $\square$ Cabriolet}

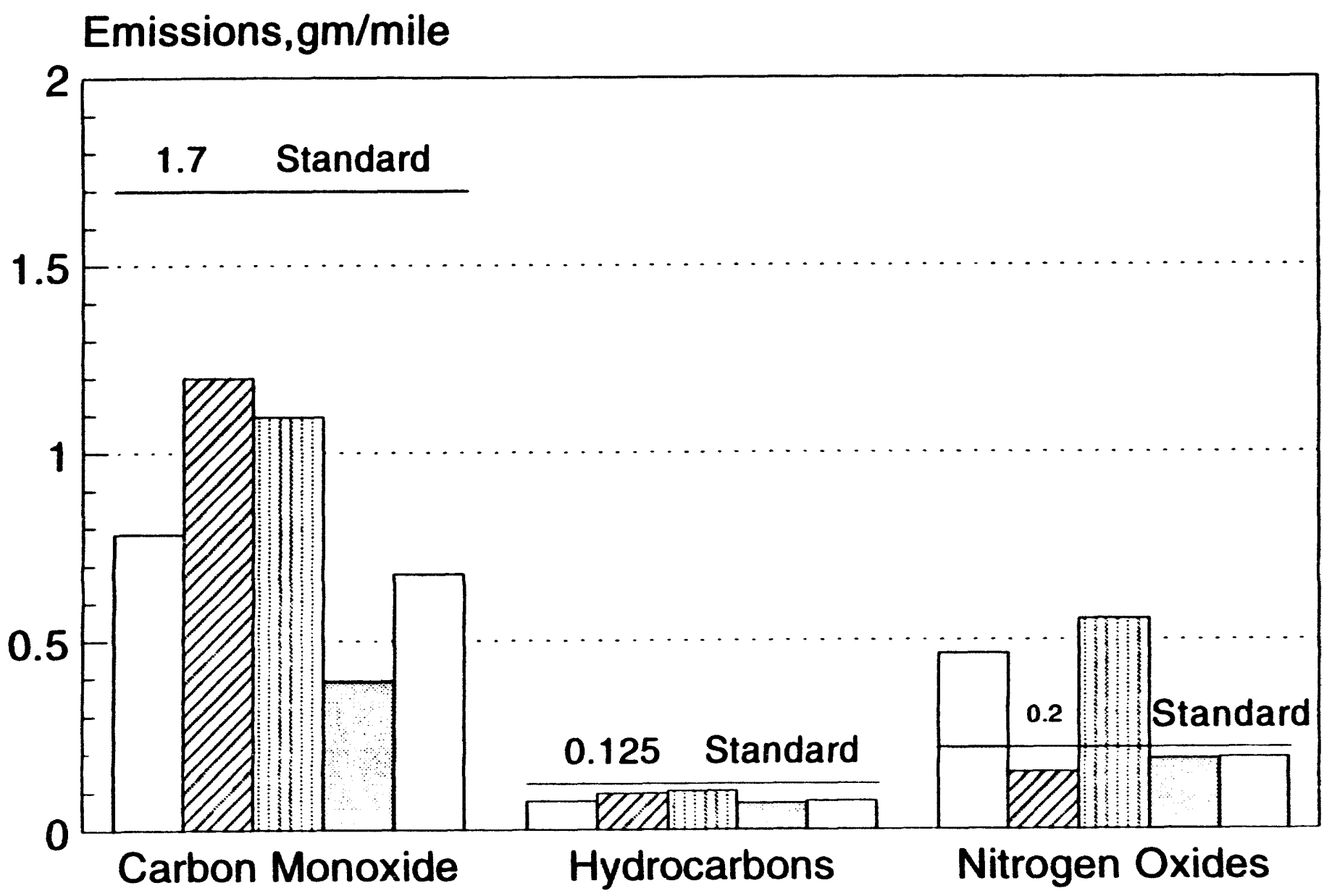

$25 \%$ oxygen, nitrogen oxides conversion efficiency of $80 \%$

FIGURE 3.19 Potential of Oxygen-Enriched Intake Air to Meet 2004 Standards 


\section{CONCLUSIONS AND RECOMMENDATIONS}

\subsection{CONCLUSIONS}

On the basis of the results of this experiment, it is clear that even with a production vehicle, oxygen enrichment yields benefits. These benefits were the reductions in carbon monoxide and hydrocarbon emissions from the engine and from the catalytic converter, especially during the cold phase of the FTP emissions test. This technique could be an alternative to the heated catalytic converter. The tests showed that oxygen-enriched air reduced the levels of hydrocarbons and carbon monoxide in the engine chamber. The tests also established that the higher oxygen content in the exhaust, not the higher exhaust temperature, accelerated the catalytic reactions leading to substantial reductions in carbon monoxide emissions in the cold phase. In addition, fewer hydrocarbons were present to compete with the carbon monoxide for the oxygen in the catalytic converter.

The hydrocarbon speciation results clearly indicate that reactive species (such as 1,3 butadiene) were remarkably reduced, both in the engine and in the catalytic converter, with the oxygen-enriched air. Similarly, both formaldehyde and acetaldehyde were reduced drastically in the engine, while modest reductions were made in the catalytic converter. The $60 \%$ reduction in ozone emissions with the 25\%-oxygen-content air (compared with normal air) is another significant benefit of this technology.

The significant increase in engine-out $\mathrm{NO}_{\mathrm{x}}$ emissions (in all phases of the FTP emissions test) was expected, because the oxygen-enriched air increased the flame speed, and combustion progressed rapidly to produce extremely hot gases. Even though these gases had more time (because of a shorter combustion duration) to cool down during the engine expansion stroke, cooling was not rapid enough to quench the gases and prevent additional $\mathrm{NO}_{x}$ formation. The increase in the catalytic converter-out $\mathrm{NO}_{x}$ was exacerbated by reduced converter efficiency under the oxidizing environment and by the extremely high $\mathrm{NO}_{x}$ concentration in the exhaust gas.

\subsection{RECOMIMENDATIONS}

The most significant reductions in both hydrocarbons and carbon monoxide due to oxygen enrichment were observed at the beginning of the cold phase of the FPT emissions test; these observations should be given serious consideration. In this experiment, no modifications were made to the oxygen-sensing or the fuel-management systems; thus, the engine must have been running leaner than necessary in the first two to three minutes because of the inadequate response of the system to the oxygen-enriched air in the cold phase. Obviously, the engine itself could be re-optimized for oxygen-enriched-air operation; for example, the timing retardation limit could be extended. Another possible design change would be to lower the engine compression ratio to reduce the knocking sensitivity. 
If the algorithm and oxygen sensor of the air/fuel-management systems were modified to accommodate the excess oxygen, the $\mathrm{NO}_{\mathrm{x}}$ emissions would be reduced in the beginning of the cold phase, while carbon monoxide emissions would also be reduced. It is also recommended that the instantaneous emissions of carbon monoxide, hydrocarbons, and $\mathrm{NO}_{\mathrm{x}}$ (both from the engine and from the catalytic converter) be measured to find out their real-time characteristics. Hydrocarbon speciation for the first two to three minutes of the cold-phase emissions would also reveal which hydrocarbons are emitted and abolished in the catalytic converter.

The results of this experiment suggest that the engine is more tolerant of a lean-burn operation (lack of misfiring problems) with oxygen enrichment. Thus, the oxygen-enriched air may improve the combustion stability of current lean-burn engines. Oxygen enrichment also has the potential of further increasing the lean-burn limit of such engines (perhaps as high as $30: 1$ ) without causing misfiring and other problems. It is highly recommended that oxygen-enrichment experiments be carried out on a lean-burn engine.

On the basis of the emissions results, it is estimated that several low- $\mathrm{NO}_{\mathrm{x}}$-emission vehicles (presently in service) could meet the year 2004 (Tier II) emissions standards if they used 25\%-oxygen-content air and were equipped with catalytic converters with $80 \%$ conversion efficiency for $\mathrm{NO}_{\mathrm{x}}$. Such a bench-mark experiment should be done to demonstrate that oxygen enrichment is a viable way to reduce emissions from older vehicles, allowing them to meet future emissions standards. Further studies should then concentrate on economic assessment of an oxygen-enrichment system.

With respect to methanol and ethanol, one of the potential benefits may be slightly improved fuel efficiency. Because of the excellent anti-knocking quality of these alternative fuels, the timing does not have to be retarded as much as for gasoline-fueled operation. Oxygen-enriched air will probably reduce aldehyde emissions; the extent of the reduction merits investigation. Experiments with oxygenated gasoline (with a known oxygen content) should be run so that results can be compared with the oxygen-enriched-air results (with an equal amount of oxygen). Experimental results would then show if use of oxygen enrichment or oxygenated gasoline would be a better way to reduce carbon monoxide, hydrocarbon, and aldehyde emissions. Experiments with gasoline containing a high aromatic content should also be run with oxygen-enriched air to determine if smoother combustion, with fewer pollutants, could be achieved.

A prototype oxygen-enrichment system (using a polymeric membrane) can be retrofitted into a conventional vehicle to show that such a system is feasible and that tangible emission benefits result. Even though a retrofit membrane oxygen-enrichment system might be bulky and not optimized, a successful vehicle demonstration would certainly position the technique as a viable emission abatement scheme. Upon completion of a successful vehicle demonstration, this system could then be recommended to the automotive and oil industries and to the various government pollution control agencies. A prototype vehicle system demonstration would pave the way for commercialization of the oxygen-enrichment technology in the future. 


\section{REFERENCES}

1. Wartinbee, Jr., W.J., 1971, "Emissions Study of Oxygen Enriched Air," Society of Automotive Engineers SAE 710606.

2. Willumeit, H.P., and M. Bauer, 1988, "Emissions and Performance of an S.I. Engine Inducting Oxygen-Enriched Combustion Air," Motortechnische Zeitschrift 49, 4, pp. 149-152.

3. Kajitani, S., N. Sawa, T. McComiskey, and K.T. Rhee, 1992, "A Spark Ignition Engine Operated by Oxygen Enriched Air," Society of Automotive Engineers SAE 922174.

4. Alternative Fuels Data from National Renewable Energy Laboratory (NREL), Aug. 1993.

5. Charkraborty, B.B., and R. Long, 1968, "The Formation of Soot and Polycyclic Aromatic Hydrocarbons in Diffusion Flames," Parts I, II and III, Combustion and Flame, 12, pp. 226-236, pp. 237-242, and pp. 469-476.

6. California Air Resources Board Reactivity (MIR and MOIR) Assignments, CARB, Nov. 1991.

7. Control of Air Pollution from New Motor Vehicle and New Vehicle Engine - Federal Certification Results for 1991 Model Year, 1991, U.S. Environmental Protection Agency. 
APPENDIX:

EQUIPMENT AND DATA 


\title{
APPENDLX:
}

\section{EQUIPMENT AND DATA}

\section{A.1 EQUIPMENT PHOTOGRAPHS}

Figure A.1 Total Oxygen Enrichment System.

Figure A.2 Oxygen Air Mixing Chamber.

\begin{abstract}
A.2 DATA
The large volume of data collected for this experiment cannot be reproduced here in detail. The emission data for carbon monoxide, hydrocarbons, oxides of nitrogen, and carbon dioxide are included here. In addition, the hydrocarbon speciation data for methane, benzene, 1,3-butadiene, formaldehyde, acetaldehyde, and methanol are included. All the data have been recorded both on paper and on 3.5-in. microdisk.
\end{abstract}

Tables A.2.1 through A.2.8 give additional experimental data. 


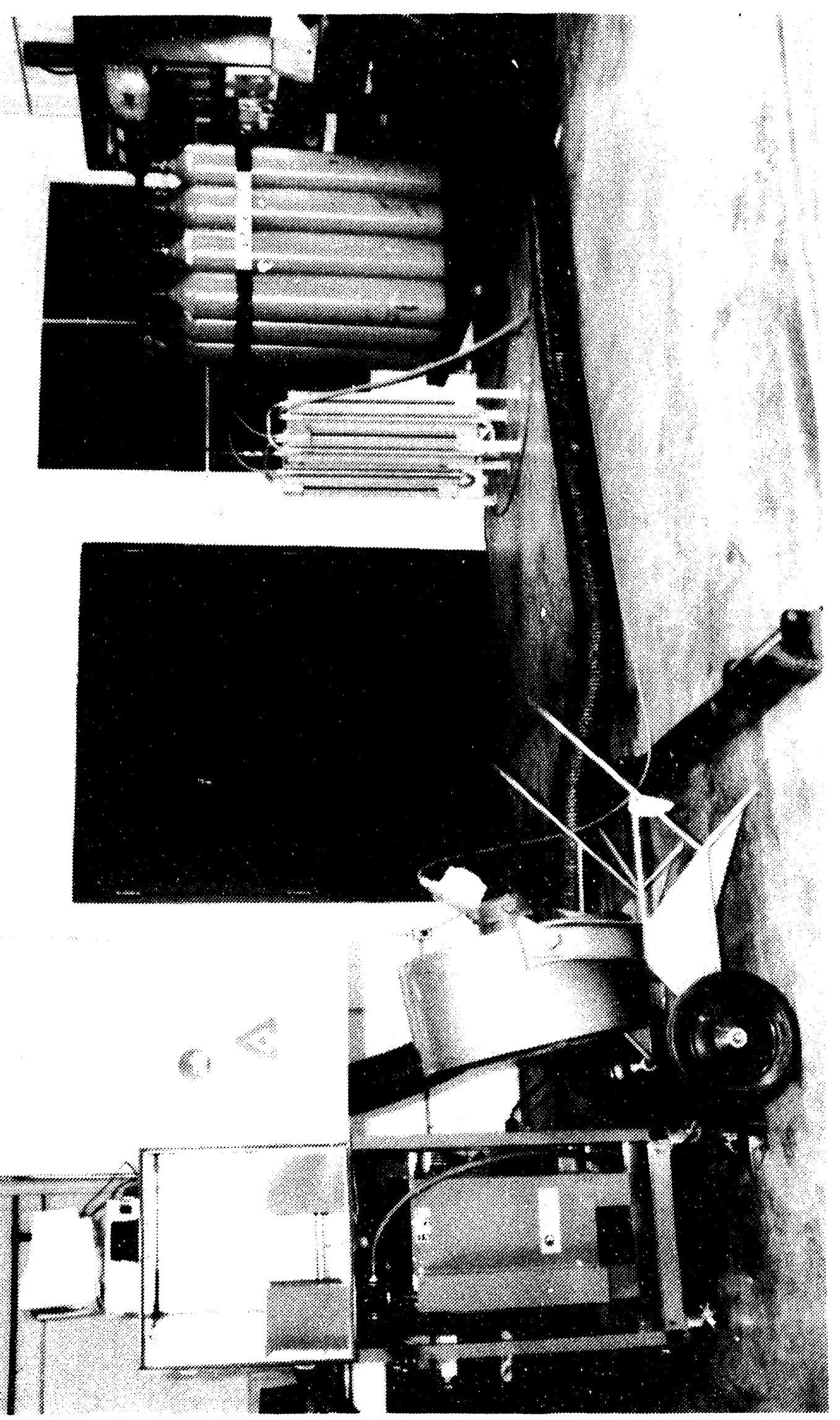

最 


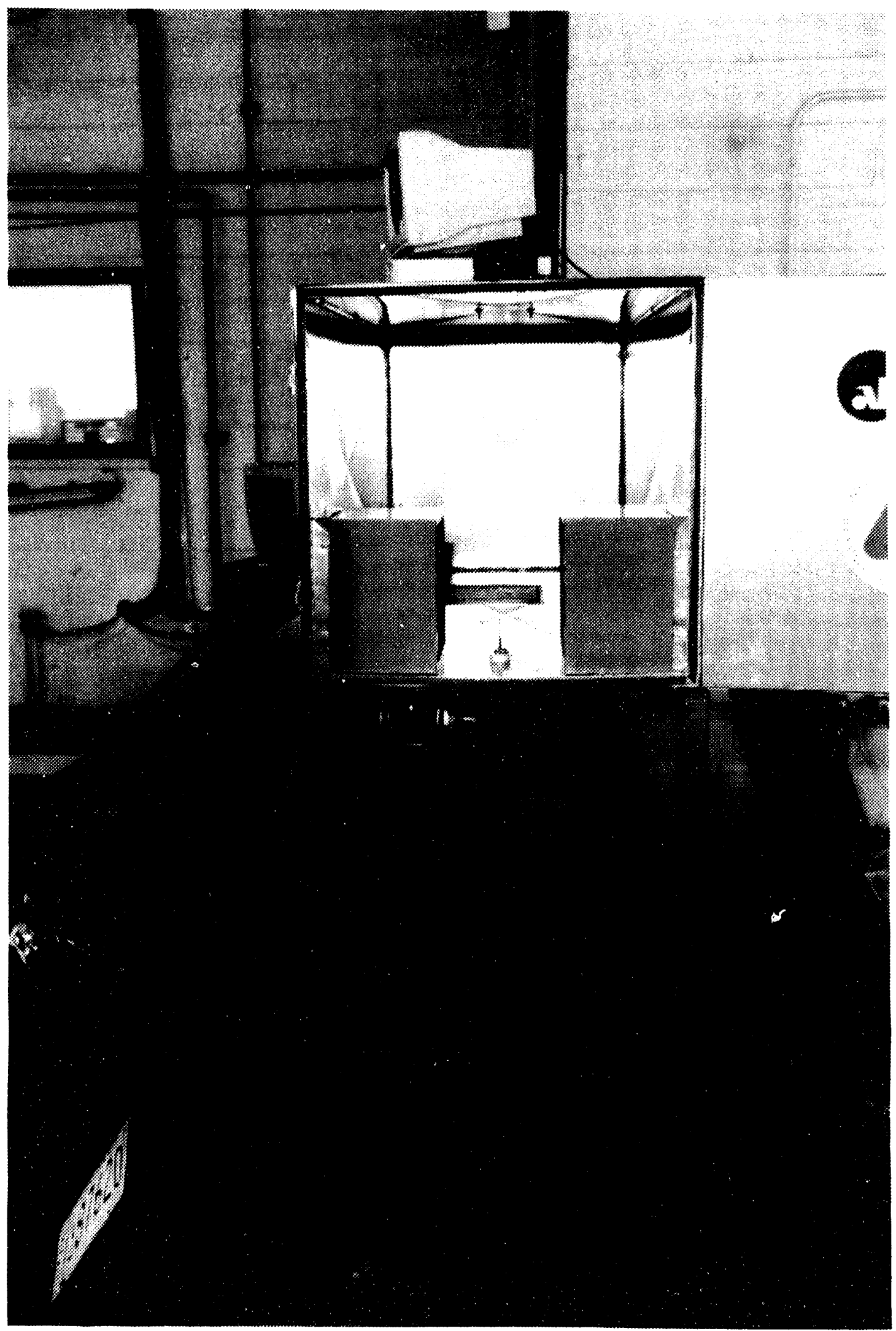

FIGURE A.2 Oxygen Air Mixing Chamber 
TABLE A.2.1 Engine-Out Emissions

\begin{tabular}{|c|c|c|c|c|c|c|c|c|c|}
\hline $\begin{array}{l}\text { Test Date } \\
\text { Test Number } \\
\text { Intake Air } 02(\%) \\
\text { Type }\end{array}$ & $\begin{array}{r}090192 \\
2572 \\
21\end{array}$ & $\begin{array}{r}090292 \\
2575 \\
21\end{array}$ & $\begin{array}{r}090992 \\
2580 \\
21\end{array}$ & $\begin{array}{r}091092 \\
2582 \\
25\end{array}$ & $\begin{array}{c}091192 \\
2585 \\
25 \\
\text { Engine Out }\end{array}$ & $\begin{array}{r}100192 \\
2610 \\
25\end{array}$ & $\begin{array}{r}090392 \\
2576 \\
28\end{array}$ & $\begin{array}{r}090492 \\
2578 \\
28\end{array}$ & $\begin{array}{r}100692 \\
2615 \\
28\end{array}$ \\
\hline \multicolumn{10}{|l|}{ Bag 1 (gm/mile) } \\
\hline HC & 2.91 & 3.46 & 2.92 & 1.64 & 1.43 & 1.52 & 1.06 & 1.16 & 1.13 \\
\hline $\mathrm{CO}$ & 17.75 & 18.18 & 18.80 & 13.09 & 12.63 & 13.11 & 9.55 & 9.96 & 10.87 \\
\hline $\mathrm{NO}_{\mathbf{x}}$ & 2.87 & 2.88 & 3.11 & 9.98 & 9.89 & 9.93 & 11.90 & 13.05 & 14.42 \\
\hline $\mathrm{CO}_{2}$ & 444.96 & 440.58 & 444.42 & 462.70 & 437.53 & 465.63 & 469.09 & 495.20 & 567.96 \\
\hline MPG & 18.4 & 18.4 & 18.3 & 18.1 & 19.1 & 18.0 & 18.1 & 17.2 & 15.0 \\
\hline \multicolumn{10}{|l|}{ Bag 2 (gm/mile) } \\
\hline $\mathrm{HC}$ & 2.74 & 2.93 & 2.74 & 1.32 & 1.32 & 1.41 & 1.03 & 1.08 & 1.07 \\
\hline $\mathrm{CO}$ & 15.26 & 15.03 & 13.77 & 17.49 & 15.30 & 16.15 & 15.11 & 15.35 & 15.00 \\
\hline $\mathrm{NO}_{\mathbf{z}}$ & 1.78 & 1.62 & 1.79 & 7.61 & 7.46 & 7.70 & 10.58 & 10.75 & 11.50 \\
\hline $\mathrm{CO}_{2}$ & 447.89 & 441.79 & 450.10 & 493.60 & 441.07 & 461.99 & 489.20 & 490.72 & 512.23 \\
\hline MPG & 18.4 & 18.6 & 18.4 & 16.8 & 18.8 & 18.0 & 17.1 & 17.1 & 16.4 \\
\hline \multicolumn{10}{|l|}{ Bag 3 (gm/mile) } \\
\hline $\overrightarrow{H C}$ & 2.14 & 2.14 & 2.16 & 1.05 & 1.05 & 1.11 & 0.86 & 0.85 & 0.82 \\
\hline $\mathrm{CO}$ & 12.25 & 10.78 & 11.48 & 11.25 & 11.14 & 11.25 & 10.07 & 12.20 & 10.33 \\
\hline $\mathrm{NO}_{\mathbf{x}}$ & 2.58 & 2.36 & 2.74 & 8.36 & 8.66 & 8.55 & 11.18 & 11.46 & 11.65 \\
\hline $\mathrm{CO}_{2}$ & 378.16 & 344.34 & 381.23 & 386.02 & 389.03 & 398.61 & 420.80 & 440.32 & 444.52 \\
\hline MPG & 21.9 & 24.0 & 21.8 & 21.7 & 21.6 & 21.0 & 20.1 & 19.1 & 19.1 \\
\hline \multicolumn{10}{|l|}{$\begin{array}{l}\text { Weighted Ave. } \\
\text { (gm/mile) }\end{array}$} \\
\hline HC & 2.61 & 2.83 & 2.61 & 1.31 & 1.27 & 1.35 & 0.99 & 1.03 & 1.01 \\
\hline $\mathrm{CO}$ & 14.95 & 14.52 & 14.18 & 14.87 & 13.61 & 14.18 & 12.57 & 13.37 & 12.86 \\
\hline $\mathrm{NO}_{x}$ & 2.23 & 2.08 & 2.32 & 8.31 & 8.29 & 8.40 & 11.02 & 11.42 & 12.15 \\
\hline $\mathrm{CO}_{2}$ & 428.10 & 414.98 & 429.83 & 457.67 & 426.05 & 445.41 & 466.24 & 477.83 & 505.15 \\
\hline MPG & 19.3 & 19.8 & 19.2 & 18.2 & 19.6 & 18.7 & 18.1 & 17.6 & 16.7 \\
\hline
\end{tabular}


TABLE A.2.2 Averaged Engine-Out Emissions

\begin{tabular}{|c|c|c|c|}
\hline & $21 \%$ Oxygen & $25 \%$ Oxygen & $28 \%$ Oxygen \\
\hline \multicolumn{4}{|c|}{ Bag 1 (gm/mile) } \\
\hline $\mathrm{HC}$ & 3.10 & 1.53 & 1.12 \\
\hline $\mathrm{CO}$ & 18.24 & 12.94 & 10.13 \\
\hline $\mathrm{NO}_{\mathrm{x}}$ & 2.95 & 9.93 & 13.12 \\
\hline $\mathrm{CO}_{2}^{2}$ & 443.32 & 455.29 & 510.75 \\
\hline MPG & 18.4 & 18.4 & 16.8 \\
\hline \multicolumn{4}{|c|}{ Bag 2 (gm/mile) } \\
\hline $\mathrm{HC}$ & 2.80 & 1.35 & 1.06 \\
\hline $\mathrm{CO}$ & 14.69 & 16.31 & 15.15 \\
\hline NO & 1.73 & 7.59 & 10.94 \\
\hline $\mathrm{CO}_{2}$ & 446.59 & 465.55 & 497.38 \\
\hline MPG & 18.5 & 17.9 & 16.9 \\
\hline \multicolumn{4}{|c|}{ Bag 3 (gm/mile) } \\
\hline $\mathrm{HC}$ & 2.15 & 1.07 & 0.84 \\
\hline $\mathrm{CO}$ & 11.50 & 11.21 & 10.87 \\
\hline $\mathrm{NO}_{x}$ & 2.56 & 8.52 & 11.43 \\
\hline $\mathrm{CO}_{2}^{2}$ & 367.91 & 391.22 & 435.21 \\
\hline MPG & 22.6 & 21.4 & 19.4 \\
\hline \multicolumn{4}{|c|}{$\begin{array}{l}\text { Weighted Ave. } \\
\text { (gm/mile) }\end{array}$} \\
\hline $\mathrm{HC}$ & 2.68 & 1.31 & 1.01 \\
\hline $\mathrm{CO}$ & 14.55 & 14.22 & 12.93 \\
\hline $\mathrm{NO}_{\mathrm{x}}$ & 2.21 & 8.33 & 11.53 \\
\hline $\mathrm{CO}_{2}$ & 424.30 & 443.04 & 483.07 \\
\hline MPG & 19.4 & 18.8 & 17.5 \\
\hline
\end{tabular}


TABLE A.2.3 Catalytic Converter-Out Emissions

\begin{tabular}{|c|c|c|c|c|c|c|c|c|c|}
\hline $\begin{array}{l}\text { Test Date } \\
\text { Test Number } \\
\text { Intake Air } 02(\%) \\
\text { Type }\end{array}$ & $\begin{array}{r}091592 \\
2588 \\
21\end{array}$ & $\begin{array}{r}091692 \\
2593 \\
21\end{array}$ & $\begin{array}{r}092492 \\
2600 \\
21\end{array}$ & $\begin{array}{r}091892 \\
2594 \\
25 \\
\end{array}$ & $\begin{array}{r}092192 \\
2596 \\
25 \\
\text { nverter } 0\end{array}$ & $\begin{array}{r}092592 \\
2602 \\
+\quad 25 \\
\end{array}$ & $\begin{array}{r}092292 \\
2597 \\
28\end{array}$ & $\begin{array}{r}092392 \\
2599 \\
28\end{array}$ & $\begin{array}{r}092992 \\
2606 \\
28\end{array}$ \\
\hline \multicolumn{10}{|l|}{ Bag 1 (gm/mile) } \\
\hline HC & 0.76 & 0.86 & 1.01 & 0.39 & 0.78 & 0.40 & 0.37 & 0.32 & 0.43 \\
\hline $\mathrm{CO}$ & 6.08 & 8.93 & 13.46 & 2.11 & 5.68 & 2.20 & 2.33 & 1.67 & 1.54 \\
\hline $\mathrm{NO}_{x}$ & 1.19 & 1.04 & 0.96 & 6.43 & 5.91 & 6.18 & 9.71 & 11.61 & 11.06 \\
\hline $\mathrm{CO}_{2}^{x}$ & 455.08 & 467.39 & 466.57 & 482.34 & 478.36 & 492.54 & 508.08 & 533.96 & 514.24 \\
\hline MPG & 18.9 & 18.3 & 18.0 & 18.2 & 18.0 & 17.8 & 17.2 & 16.4 & 17.1 \\
\hline \multicolumn{10}{|l|}{ Bag 2 (gm/mile) } \\
\hline $\mathrm{HC}$ & 0.09 & 0.09 & 0.08 & 0.06 & 0.05 & 0.04 & 0.02 & 0.05 & 0.95 \\
\hline $\mathrm{CO}$ & 1.32 & 1.67 & 1.21 & 2.03 & 1.09 & 1.21 & 0.54 & 1.14 & 1.15 \\
\hline $\mathrm{NO}_{x}$ & 0.33 & 0.31 & 0.37 & 2.46 & 2.96 & 2.74 & 5.40 & 5.68 & $5.1 E$ \\
\hline $\mathrm{CO}_{2}$ & 476.36 & 482.92 & 474.37 & 488.63 & 480.99 & 485.54 & 510.84 & 527.74 & 514.58 \\
\hline MPG & 18.5 & 18.2 & 18.5 & 18.0 & 18.3 & 18.1 & 17.3 & 16.7 & 17.1 \\
\hline \multicolumn{10}{|l|}{ Bag 3 (gm/mile) } \\
\hline $\mathrm{HC}$ & 0.24 & 0.13 & 0.16 & 0.06 & 0.07 & 0.06 & 0.04 & 0.04 & 0.04 \\
\hline $\mathrm{CO}$ & 3.73 & 1.60 & 1.43 & 1.24 & 1.09 & 0.89 & 0.44 & 0.77 & 1.00 \\
\hline $\mathrm{NO}_{\mathrm{x}}$ & 0.51 & 0.54 & 0.55 & 3.64 & 3.80 & 3.56 & 6.29 & 7.62 & 6.00 \\
\hline $\mathrm{CO}_{2}^{\mathrm{x}}$ & 393.03 & 413.27 & 399.36 & 425.32 & 419.94 & 418.84 & 450.74 & 453.89 & 439.57 \\
\hline MPG & 22.1 & 21.2 & 22.0 & 20.7 & 20.9 & 21.0 & 19.6 & 19.4 & 20.0 \\
\hline \multicolumn{10}{|l|}{$\begin{array}{l}\text { Weighted Ave. } \\
\text { (gm/mile) }\end{array}$} \\
\hline $\mathrm{HC}$ & 0.27 & 0.26 & 0.30 & 0.13 & 0.21 & 0.12 & 0.10 & 0.10 & 0.13 \\
\hline $\mathrm{CO}$ & 2.97 & 3.15 & 3.83 & 1.83 & 2.04 & 1.32 & 0.88 & 1.15 & 1.19 \\
\hline $\mathrm{NO}_{\mathrm{x}}$ & 0.56 & 0.52 & 0.54 & 3.60 & 3.80 & 3.67 & 6.54 & 7.44 & 6.61 \\
\hline $\mathrm{CO}_{2}$ & 449.05 & 460.62 & 452.06 & 470.17 & 463.68 & 468.64 & 493.74 & 508.70 & 493.92 \\
\hline MPG & 19.4 & 18.9 & 19.3 & 18.7 & 18.9 & 18.8 & 17.8 & 17.3 & 17.8 \\
\hline
\end{tabular}


TABLE A.2.4 Averaged Catalytic Converter-Out Emissions

\begin{tabular}{|c|c|c|c|}
\hline & $21 \%$ Oxygen & $25 \%$ Oxygen & $28 \%$ Oxygen \\
\hline \multicolumn{4}{|c|}{ Bag 1 (mg/mile) } \\
\hline HC & 0.88 & 0.52 & 0.37 \\
\hline $\mathrm{CO}$ & 9.49 & 3.33 & 1.85 \\
\hline $\mathrm{NO}_{\mathrm{x}}$ & 1.06 & 6.17 & 10.79 \\
\hline $\mathrm{CO}_{2}$ & 463.01 & 484.41 & 518.76 \\
\hline MPG & 18.4 & 18.0 & 16.9 \\
\hline \multicolumn{4}{|c|}{ Bag 2 (mg/mile) } \\
\hline HC & 0.09 & 0.05 & 0.04 \\
\hline $\mathrm{CO}$ & 1.40 & 1.44 & 0.94 \\
\hline NO & 0.34 & 2.72 & 5.41 \\
\hline $\mathrm{CO}_{2}^{\mathrm{x}}$ & 477.88 & 485.05 & 517.72 \\
\hline MPG & 18.4 & 18.1 & 17.0 \\
\hline \multicolumn{4}{|c|}{ Bag 3 (mg/mile) } \\
\hline $\mathrm{HC}$ & 0.18 & 0.06 & 0.04 \\
\hline $\mathrm{CO}$ & 2.25 & 1.07 & 0.74 \\
\hline $\mathrm{NO}_{\mathrm{x}}$ & 0.53 & 3.67 & 6.64 \\
\hline $\mathrm{CO}_{2}^{*}$ & 401.89 & 421.37 & 448.07 \\
\hline MPG & 21.8 & 20.9 & 19.7 \\
\hline \multicolumn{4}{|c|}{$\begin{array}{l}\text { Weighted Ave. } \\
\text { (mg/mile) }\end{array}$} \\
\hline $\mathrm{HC}$ & 0.28 & 0.15 & 0.11 \\
\hline $\mathrm{CO}$ & 3.32 & 1.73 & 1.07 \\
\hline $\mathrm{NO}_{\mathrm{x}}$ & 0.54 & 3.69 & 6.86 \\
\hline $\mathrm{CO}_{2}^{n}$ & 453.91 & 467.50 & 498.79 \\
\hline MPG & 19.2 & 18.8 & 17.6 \\
\hline
\end{tabular}


TABLE A.2.5 Selected Engine-Out Hydrocarbon Emissions

\begin{tabular}{|c|c|c|c|c|c|c|c|c|c|}
\hline $\begin{array}{l}\text { Test Date } \\
\text { Test Number } \\
\text { Intake Air } 02(\%) \\
\text { Type }\end{array}$ & $\begin{array}{r}090192 \\
2572 \\
21\end{array}$ & $\begin{array}{r}090292 \\
2575 \\
21\end{array}$ & $\begin{array}{r}090992 \\
2580 \\
21\end{array}$ & $\begin{array}{r}091092 \\
2582 \\
25 \\
\end{array}$ & $\begin{array}{c}091192 \\
2585 \\
25 \\
\text { Engine Out }\end{array}$ & $\begin{array}{r}100192 \\
2610 \\
25\end{array}$ & $\begin{array}{r}090392 \\
2576 \\
28\end{array}$ & $\begin{array}{r}090492 \\
2578 \\
28\end{array}$ & $\begin{array}{r}100692 \\
2615 \\
28\end{array}$ \\
\hline \multicolumn{10}{|l|}{ Bag 1 (mg/mile) } \\
\hline Methane & NA & 114 & 100 & 72 & 60 & NA & 52 & 68 & NA \\
\hline Benzene & NA & 144 & 126 & 79 & 80 & NA & 54 & 51 & NA \\
\hline 1,3-Butadiene & NA & 33 & 9 & 7 & 2 & NA & 3 & 6 & NA \\
\hline Formaldehyde & NA & 110 & 113 & 36 & 49 & NA & 80 & 26 & NA \\
\hline Acetaldehyde & NA & 28 & 23 & 5 & 11 & NA & 14 & 2 & NA \\
\hline Methanol & NA & 15 & 17 & 9 & 11 & NA & 10 & 10 & NA \\
\hline \multicolumn{10}{|l|}{ Bag 2 (mg/mile) } \\
\hline Methane & NA & 86 & 86 & 63 & 71 & NA & 59 & 61 & NA \\
\hline Benzene & NA & 100 & 132 & 60 & 69 & NA & 64 & 61 & NA \\
\hline 1,3-Butadiene & NA & 33 & 6 & 6 & 0 & NA & 3 & 4 & NA \\
\hline Formaldehyde & NA & 96 & 116 & 70 & 65 & NA & 28 & 78 & NA \\
\hline Acetaldehyde & NA & 24 & 22 & 15 & 16 & NA & 4 & 14 & NA \\
\hline Methanol & NA & 16 & 12 & 9 & 9 & NA & 4 & 7 & NA \\
\hline \multicolumn{10}{|l|}{ Bag 3 (mg/mile) } \\
\hline Methane & NA & 65 & 67 & 53 & 52 & NA & 43 & 46 & NA \\
\hline Benzene & NA & 70 & 85 & 46 & 46 & NA & 46 & 46 & NA \\
\hline 1,3-Butadiene & NA & 20 & 7 & 6 & 2 & NA & 3 & 4 & NA \\
\hline Formaldehyde & NA & 93 & 103 & 47 & 50 & NA & 52 & 50 & NA \\
\hline Acetaldehyde & NA & 19 & 19 & 10 & 12 & NA & 10 & 10 & NA \\
\hline Methanol & NA & 8 & 13 & 6 & 12 & NA & 8 & 13 & NA \\
\hline \multicolumn{10}{|l|}{$\begin{array}{l}\text { Weighted Ave. } \\
\text { (mg/mile) }\end{array}$} \\
\hline Methane & NA & 86 & 84 & 62 & 64 & NA & 53 & 58 & NA \\
\hline Benzene & NA & 101 & 118 & 60 & 65 & NA & 57 & 55 & NA \\
\hline 1,3-Butadiene & NA & 30 & 7 & 6 & 1 & NA & 3 & 5 & NA \\
\hline Formaldehyde & NA & 98 & 112 & 56 & 58 & NA & 45 & 60 & NA \\
\hline Acetaldehyde & NA & 24 & 22 & 12 & 14 & NA & 8 & 10 & $\mathrm{NA}$ \\
\hline Methanol & NA & 14 & 13 & 8 & 11 & NA & 6 & 9 & NA \\
\hline
\end{tabular}


TABLE A.2.6 Averaged Engine-Out Hydrocarbon Emissions

$21 \%$ Oxygen $25 \%$ Oxygen $28 \%$ Oxygen

Bag 1 (mg/mile)

Methane

Benzene

1,3-Butadiene

Formaldehyde

Acetaldehyde

Methanol

107

135

21

112

26

16

Bag 2 (mg/mile)

Methane

Benzene

1,3-Butadiene

Formaldehyde

Acetaldehyde

Methanol

Bag 3 (mg/mile)

Methane

Benzene

1,3-Butadiene

Formaldehyde

Acetaldehyde

Methanol

Weighted Ave.

(mg/mile)

Methane

Benzene

1,3-Butadiene

Formaldehyde

Acetaldehyde

Methanol
86

116

20

106

23

14

66

78

14

98

19

11

85

110

19

105

23

14

66

80

5

43

8

10

60

53

5

53

8

10

\begin{tabular}{rrr}
86 & 67 & 60 \\
6 & 65 & 63 \\
0 & 3 & 4 \\
3 & 68 & 53 \\
4 & 16 & 9 \\
\hline
\end{tabular}

\begin{tabular}{rrr}
53 & 45 \\
46 & 46 \\
\hline 9 & 4 \\
99 & 51 \\
\hline & 11 & 10 \\
9 & 11
\end{tabular}


TABLE A.2.7 Selected Catalytic Converter-Out Hydrocarbon Emissions

\begin{tabular}{|c|c|c|c|c|c|c|c|c|c|}
\hline $\begin{array}{l}\text { Test Date } \\
\text { Test Number } \\
\text { Intake Air } 02(\%) \\
\text { Type }\end{array}$ & $\begin{array}{r}091592 \\
2588 \\
21\end{array}$ & $\begin{array}{r}091692 \\
2593 \\
21\end{array}$ & $\begin{array}{r}092492 \\
2600 \\
21\end{array}$ & $\begin{array}{r}091892 \\
2594 \\
25\end{array}$ & $\begin{array}{r}092192 \\
2596 \\
25 \\
\text { nverter }\end{array}$ & $\begin{array}{r}092592 \\
2602 \\
\quad 25\end{array}$ & $\begin{array}{r}092292 \\
2597 \\
28\end{array}$ & $\begin{array}{r}092392 \\
2599 \\
28\end{array}$ & $\begin{array}{r}092992 \\
2606 \\
28\end{array}$ \\
\hline \multicolumn{10}{|l|}{ Bag 1 (mg/mile) } \\
\hline Methane & 67 & 79 & 86 & 33 & 75 & 37 & 32 & 33 & 42 \\
\hline Benzene & 36 & 42 & 38 & 14 & 37 & 16 & 16 & 15 & 20 \\
\hline 1,3-Butadiene & 7 & 0 & 5 & 1 & 3 & 2 & 0 & 0 & 0 \\
\hline Formaldehyde & 18 & 18 & 10 & 11 & 14 & 20 & 4 & 7 & 12 \\
\hline Acetaldehyde & 5 & 5 & 4 & 2 & 4 & 4 & 0 & 0 & 0 \\
\hline Mothanol & 3 & 5 & $\mathbf{N A}$ & 5 & 2 & 1 & 3 & NA & NA \\
\hline \multicolumn{10}{|l|}{ Bag 2 (mg/mile) } \\
\hline Methane & 48 & 45 & 30 & 46 & 35 & 33 & 12 & 35 & 28 \\
\hline Benzene & 4 & 4 & 3 & 1 & 1 & 1 & 1 & 1 & 1 \\
\hline 1,3-Butadiene & 0 & 0 & 0 & 0 & 0 & 0 & 0 & 0 & 0 \\
\hline Formaldehyde & 3 & 3 & 1 & 1 & 2 & 0 & 0 & 1 & 9 \\
\hline Acetaldehyde & 0 & 0 & 1 & 0 & 0 & 0 & 0 & 0 & 0 \\
\hline Methanol & 0 & 0 & NA & 1 & 1 & 0 & 0 & NA & NA \\
\hline \multicolumn{10}{|l|}{ Bag 3 (mg/mile) } \\
\hline Methane & 52 & 39 & 33 & 30 & 33 & 26 & 21 & 25 & 25 \\
\hline Benzene & 13 & 4 & 8 & 1 & 2 & 3 & 2 & 2 & 1 \\
\hline 1,3-Butadiene & 2 & 0 & 0 & 0 & 0 & 0 & 0 & 0 & 0 \\
\hline Formaldehyde & $\mathbf{1}$ & 2 & 0 & 0 & 0 & 7 & 0 & 2 & 7 \\
\hline Acetaldehyde & 0 & 0 & 1 & 0 & 0 & 0 & 0 & 0 & 0 \\
\hline Methanol & 4 & 0 & NA & 3 & 2 & 0 & 2 & NA & NA \\
\hline \multicolumn{10}{|l|}{$\begin{array}{l}\text { Weighted Ave. } \\
\text { (mg/mile) }\end{array}$} \\
\hline Methane & 53 & 50 & 42 & 39 & 43 & 32 & 19 & 31 & 30 \\
\hline Benzene & 13 & 12 & 12 & 4 & 9 & 4 & 4 & 4 & 5 \\
\hline 1,3-Butadiene & 2 & 0 & 1 & 0 & 1 & 0 & 0 & 0 & 0 \\
\hline Formaldehyde & 6 & 6 & 3 & 3 & 4 & 6 & 1 & 2 & 9 \\
\hline Acetaldehyde & 1 & 1 & 1 & 1 & 1 & 1 & 0 & 0 & 0 \\
\hline Methanol & 2 & 1 & $\mathbf{N A}$ & 2 & 1 & 0 & 1 & NA & NA \\
\hline
\end{tabular}


TABLE A.2.8 Averaged Catalytic Converter-Out Fydrocarbon Emissions

\begin{tabular}{|c|c|c|c|}
\hline & $21 \%$ Oxygen & $25 \%$ Oxygen & $28 \%$ Oxygen \\
\hline \multicolumn{4}{|l|}{ Bag $1(\mathrm{mg} / \mathrm{mile})$} \\
\hline Methane & 77 & 48 & 36 \\
\hline Benzene & 39 & 22 & 17 \\
\hline 1,3-Butadiene & 4 & 2 & 0 \\
\hline Formaldehyde & 15 & 15 & 8 \\
\hline Acetaldehyde & 5 & 3 & 0 \\
\hline Methanol & 4 & 3 & 3 \\
\hline \multicolumn{4}{|l|}{ Bag 2 (mg/mile) } \\
\hline Methane & 41 & 38 & 25 \\
\hline Benzene & 4 & 1 & 1 \\
\hline 1,3-Butadiene & 0 & 0 & 0 \\
\hline Formaldehyde & 2 & 1 & 3 \\
\hline Acetaldehyde & 0 & 0 & 0 \\
\hline Methanol & 0 & 1 & 0 \\
\hline \multicolumn{4}{|l|}{ Bag 3 (mg/mile) } \\
\hline Methane & 41 & 30 & 24 \\
\hline Benzene & 8 & 2 & 2 \\
\hline 1,3-Butadiene & 1 & 0 & 0 \\
\hline Formaldehyde & 1 & 2 & 3 \\
\hline Acetaldehyde & 0 & 0 & 0 \\
\hline Methanol & 2 & 2 & 2 \\
\hline \multicolumn{4}{|l|}{$\begin{array}{l}\text { Weighted Ave. } \\
\text { (mg/mile) }\end{array}$} \\
\hline Methane & 48 & 38 & 27 \\
\hline Benzene & 12 & 6 & 4 \\
\hline 1,3-Butadiene & 1 & 0 & 0 \\
\hline Formaldehyde & 5 & 4 & 4 \\
\hline Acetaldehyde & 1 & 1 & 0 \\
\hline Methanol & 2 & 1 & 1 \\
\hline
\end{tabular}



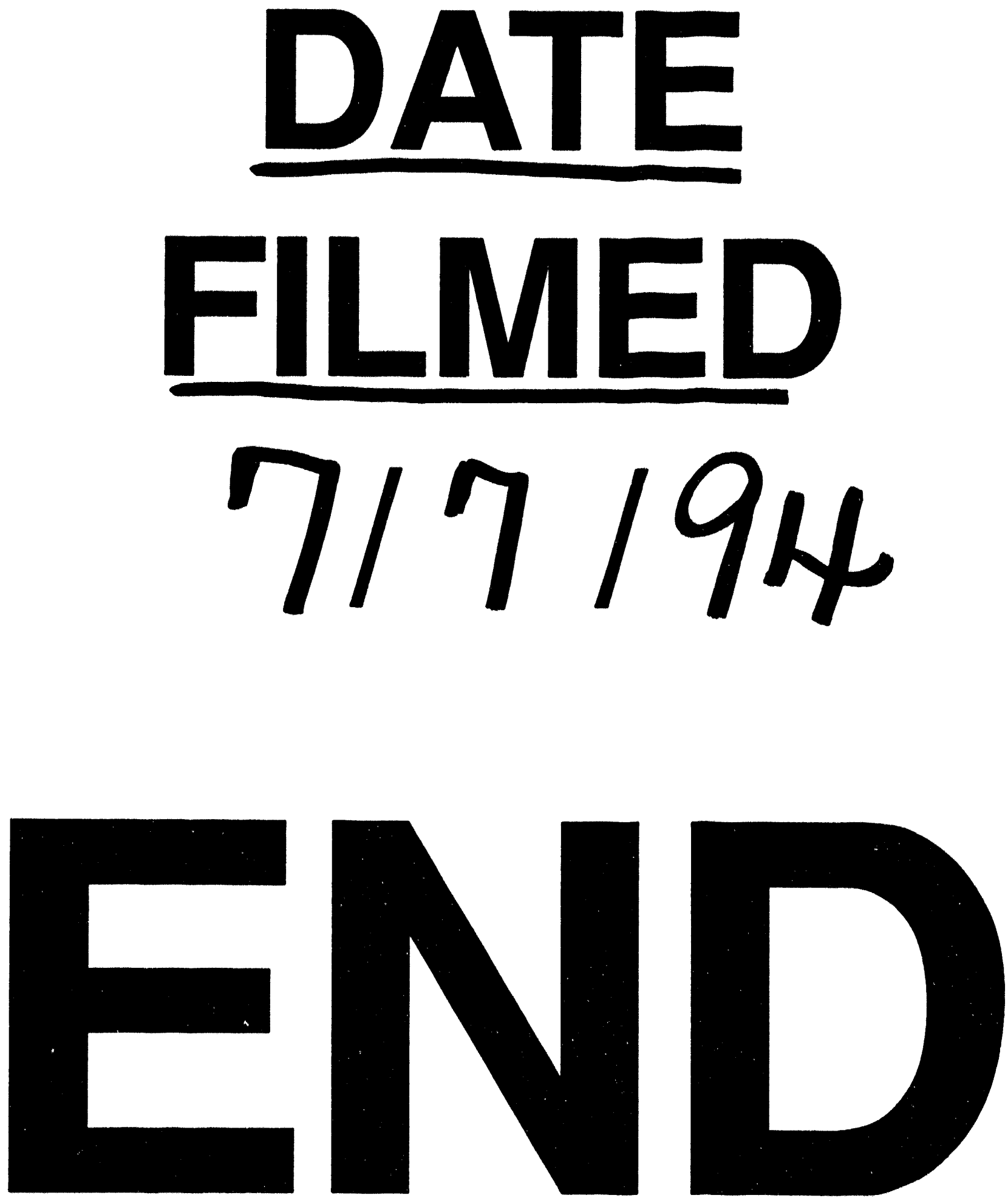
1 